OPEN ACCESS

Edited by:

David Baglietto-Vargas, University of Malaga, Spain

Reviewed by: Douglas Sawyer, Maine Medical Center, Maine Health, United States Alexandre Henriques, Neuro-Sys, France

${ }^{*}$ Correspondence: Wei-jiang Zhao weijiangzhao@jiangnan.edu.cn

Received: 01 February 2021 Accepted: 16 March 2021 Published: 09 April 2021

Citation: Ou G-y, Lin W-w, and Zhao W-j (2021) Neuregulins in Neurodegenerative Diseases. Front. Aging Neurosci. 13:662474. doi: 10.3389/fnagi.2021.662474

\section{Neuregulins in Neurodegenerative Diseases}

\author{
Guan-yong Ou ${ }^{1}$, Wen-wen Lin $^{1}$ and Wei-jiang Zhao ${ }^{1,2 *}$ \\ ${ }^{1}$ Center for Neuroscience, Shantou University Medical College, Shantou, China, ${ }^{2}$ Cell Biology Department, Wuxi School of \\ Medicine, Jiangnan University, Wuxi, China
}

Neurodegenerative diseases, including Alzheimer's disease (AD), Parkinson's disease (PD) and amyotrophic lateral sclerosis (ALS), are typically characterized by progressive neuronal loss and neurological dysfunctions in the nervous system, affecting both memory and motor functions. Neuregulins (NRGs) belong to the epidermal growth factor (EGF)-like family of extracellular ligands and they play an important role in the development, maintenance, and repair of both the central nervous system (CNS) and peripheral nervous system (PNS) through the ErbB signaling pathway. They also regulate multiple intercellular signal transduction and participate in a wide range of biological processes, such as differentiation, migration, and myelination. In this review article, we summarized research on the changes and roles of NRGs in neurodegenerative diseases, especially in AD. We elaborated on the structural features of each NRG subtype and roles of NRG/ErbB signaling networks in neurodegenerative diseases. We also discussed the therapeutic potential of NRGs in the symptom remission of neurodegenerative diseases, which may offer hope for advancing related treatment.

\section{Keywords: neuregulin, ErbB receptor, neurodegeneration, neurodegenerative diseases, treatment}

\section{INTRODUCTION}

Neurodegeneration is characterized by the progressive loss of neuronal structure and function, including the death of neurons, which deteriorates over time and eventually leads to dysfunction of the nervous system. Neurodegenerative diseases, including Alzheimer's disease (AD), Parkinson's disease (PD), Huntington's disease (HD), amyotrophic Ilateral sclerosis (ALS) and spinocerebellar ataxia (SCA; Mehta et al., 2016), are heterogeneous diseases typical to progressive deterioration of the structure and function of either the Central nervous system (CNS) or the Peripheral nervous system (PNS; Goedert and Spillantini, 2006; Masters et al., 2015), as the result of neurodegenerative processes (Mehta et al., 2016). According to different clinical and pathological characteristics, neurodegenerative diseases can be divided into acute and chronic neurodegenerative diseases (Gallucci et al., 2008). The former mainly includes cerebral ischemia (CI), brain injury (BI), and epilepsy, while the latter includes $\mathrm{AD}, \mathrm{PD}, \mathrm{HD}$, and psychiatric disorders (Gallucci et al., 2008). The clinical manifestations of neurodegenerative 
diseases mainly include impairment of learning ability, cognitive ability, as well as the memory, sensory, judgments, thinking and motor abilities to varying extents (Kaplin and Montel, 2007).

As the human life expectancy prolongs with the improvement of modern medical management and living standards, the proportion of the elderly population is gradually increasing, and the population aging is acceleratively progressing (Boland and Mark, 2012). In the meantime, the incidence of neurodegenerative diseases is also increasing. According to a recent report, neurodegenerative diseases have become extremely serious threatening human health now a days. From the year 2010-2030, the number of individuals of age 65 years or above with PD will increase by $77 \%$. For $\mathrm{AD}$, the most common neurodegenerative condition, the number of individuals affected will increase by more than $50 \%$. The increase in these and other neurodegenerative conditions will be accompanied by tremendous pressure and burden to patients, their families and even the government (Dorsey et al., 2013a,b). Although research on the mechanism and treatment of neurodegenerative diseases has developed rapidly in recent years, there are no effective medicines or drugs with high efficiency to prevent or treat these diseases (Hogan, 2014; Bateman, 2015). It is therefore a pressing challenge for neuroscientists to tackle the critical pathogenesis of neurodegenerative diseases and develop effective therapeutic means.

Accumulating evidence demonstrated that these neurodegenerative diseases exhibit similar changes at the subcellular level. Studies have found that oxidative stress (Bhat et al., 2015), mitochondrial dysfunction (Bhat et al., 2015), neuronal apoptosis (Okouchi et al., 2007), protein aggregation (Ross and Poirier, 2005) and autophagy (Ntsapi and Loos, 2016) are among the essential mechanisms underlying neurodegeneration and have been implicated in the progression of these diseases, including AD, PD and ALS.

Many causes have been reported to contribute to the development of neurodegenerative diseases, such as lack of nutrition provided to neurons or glial cells (Ntsapi and Loos, 2016), impaired axonal transmission (Patrizia et al., 2012) and metabolic pathways (Wang G.-X. et al., 2014; Spinedi and Cardinali, 2019), loss of energy due to neuronal mitochondrial damage (Bhat et al., 2015), protein misfolding (Khanam et al., 2016), neuroinflammation (Barnham et al., 2004), viral infections (Qiu et al., 2020), DNA mutations (Bao et al., 2006) and other factors. Researchers have found that many neurodegenerative diseases are characterized by protein misfolding and aggregation (Dobson, 2003; Wang X. et al., 2014; Lee et al., 2015; Lim and Yue, 2015), which are cytotoxic and can cause neuronal dysfunction. Amyloid plaques and neurofibrillary tangles (NFTs) were typically detected in the brain of $\mathrm{AD}$ patients (Selkoe, 1998). Lewy bodies formed by aggregation of $\alpha$-synuclein were found in the PD brain (Costa et al., 2009). Insoluble macromolecular complexes due to mutations in genes encoding superoxide dismutase (SOD) were found to form aggregates, which ultimately leads to motor neuronal death (van der Graaff et al., 2009).
Recently, scientists have identified the structural characteristics of toxic polyglutamine proteins that lead to neurodegenerative brain diseases and the mechanisms of early neuropathology (Kwon et al., 2018). With the increase of human life expectancy, the proportion of the aging population increases, resulting in a gradually increasing number of people suffering from neurodegenerative diseases. Although many scholars are devoted to studying the pathogenesis and progression of neurodegenerative brain diseases, they have not yet uncovered the real cause. Due to the difficulty in diagnosing these diseases at the early stage, there is still too much work to be devoted to efficient treatment (Kwon et al., 2018). Researchers have found that the coiled-helix structure of toxic polyglutamine proteins, like a twisted telephone line in molecular structure, can cause rapid deformation of neurons and early neurodegenerative diseases, such as HD and spinocerebellar ataxia (Kwon et al., 2018). These proteins are abnormally combined to form a coiled-coil structure of toxic polyglutamine proteins. Researchers also found that the coiled-coil structure of toxic polyglutamine proteins in neurons can cause early neuropathy by binding to Foxo, a transcription factor that regulates the formation of dendrites (Kwon et al., 2018).

Neuregulins (NRGs) belong to the epidermal growth factor family of extracellular ligands, participating in the regulation of normal cells and tumor cell growth and survival through the ErbB family receptor tyrosine kinases (Holbro and Hynes, 2004; Bublil and Yarden, 2007; Schneider and Eckhard, 2010). The NRG family is mainly composed of NRG1-4 isoforms, among which NRG1 plays a vital role in regulating cardiac embryo development and maintaining cell structural function (Stavroula et al., 2003). Recent studies have shown that NRG1 can also antagonize inflammatory response, regulate cell growth, and inhibit cell apoptosis (Hedhli et al., 2014). However, few studies have focused on NRG2-4. These NRGs all contain an epidermal growth factor-like domain that regulates various biological processes primarily through the ErbB receptor signaling pathway (Schneider and Eckhard, 2010).

It is still unclear about the NRGs-involved mechanisms underlying the occurrence and pathogenesis of most neurodegenerative diseases. Most of the related studies are still in the exploratory stage, with a large amount of dispute about the role of the NRG family in neurodegenerative diseases. However, many studies have proved that the interaction between NRGs and their receptors plays an important role in the pathogenesis and treatment of neurodegenerative diseases (Bublil and Yarden, 2007). Therefore, dissecting the distribution and biological function of NRGs is one of the important entry points in studying the mechanism underlying neurodegenerative diseases. In addition, NRGs can be used as targets for therapeutic or clinical trials due to their multiple roles in these diseases. Future research should also consider NRGs treatment against neurodegenerative diseases, which may increase the success rate of the application of NRGs in related treatment. In this review article, we purposed to summarize the roles of NRGs in neurodegenerative diseases to provide some guidance to future research, which may to a certain degree offer hope for the clinical treatment of neurodegenerative diseases. 


\section{CLASSIFICATION AND STRUCTURES OF NEUREGULIN}

Neuregulin (NRG) is a family of growth factors that plays multiple roles in many neurological disorders, including ALS (Song et al., 2012), brain trauma (Pankonin et al., 2009), spinal cord injury (SCI; Pankonin et al., 2009), peripheral neuropathy (Calvo et al., 2010), and schizophrenia (Wang et al., 2015). There are four $N R G$ genes that encode NRG1, 2, 3 and 4, respectively in mammals (Falls, 2003). All NRG isoforms contain a fragment encoding an epidermal growth factor (EGF)-like domain that regulates the association of NRG proteins with the ErbB receptor tyrosine kinases (Falls, 2003). It is known that the pleiotropic activities of NRGs are transduced by a set of receptor protein tyrosine kinases exhibiting structural similarity to the receptor for EGF (Gassmann and Lemke, 1997). Four transmembrane (TM) tyrosine kinases constitute the ErbB receptor family: Her1 (EGFR, ErbB1), Her2 (Neu, ErbB2), Her3 (ErbB3), and Her4 (ErbB4; Baulida et al., 1996). A large number of studies have shown the critical roles of NRGs and their receptors in cell proliferation regulation (Cespedes et al., 2018), neural crest cells differentiation and migration (Meyer et al., 1997), survival and maturation of astrocytes (Pinkas-Kramarski et al., 1994), Schwann cell development, maturation and myelination (Meyer and Birchmeier, 1995; Michailov et al., 2004; Fledrich et al., 2014; Bartus et al., 2016), growth and differentiation of epithelial, glial and muscle cells (Meyer et al., 1997), synapse formation (Fricker et al., 2011), GABAergic neuron migration (Yang et al., 1998), acute nerve injury (Fricker et al., 2011), chronic neuropathy (Fledrich et al., 2014, 2019), spinal cord injury (Bartus et al., 2016), cell fate determination (Baulida et al., 1996), and pattern establishment (Burden and Yarde, 1997) in the developing nervous systems.

\section{Structure, Distribution and Biological Functions of Neuregulin 1}

Neuregulin1 (NRG1) has been differently named as neu differentiation factor (NDF, type I), heregulin (HRG, type I), acetylcholine receptor-inducing activity (ARIA, type I), glial growth factor (GGF, type II), and sensory and motor neuronderived factor (SMDF, type III; Kataria et al., 2019), which is the most widely studied among all NRG subtypes identified upto now. The NRG1 was originally extracted from breast cancer cells (Brockes, 1983), and was subsequently extracted from the bovine brain and pituitary gland (Lemke and Brockes, 1984). The NRG1 gene is located on chromosome 8 of both human and mouse, and can encode 21 exons (Steinthorsdottir et al., 2004). At least 31 species can be generated by selective splicing and promoter differences, including soluble and membrane-tethered full-length subtypes (Falls, 2003). Differential splicing of NRG1 gene can produce at least six NRG1 (I-VI) subtypes with an extracellular domain, of which NRG1 type I to III are by far the most studied ones (Falls, 2003). All subtypes of NRG1 contain an EGF-like domain that can be further classified as $\alpha$ or $\beta$ (Rosnack et al., 1994; Jacobsen et al., 1996). Different from soluble NRG1, the membrane-tethered isoform contains a transmembrane (TM) domain and an intracellular domain (ICD). The ICD can be further characterized as ICD a, b, and $c$. The structure that bridges the extracellular and TM domains is called stem ( $\mathrm{S}$ ) and can be further divided into S1, S2 and S4 (Zhao, 2013a). Proteolysis of NRG1 precursor proteins is a highly regulated biological process, releasing soluble domains to form autocrine/paracrine loops. However, the recruitment of S3 containing stop codon terminates the extension of the extracellular domain into the cytoplasm, leading to the formation of non-membrane anchored NRG1 $\alpha / \beta$ (Zhao, 2013a; Figure 1).

Researchers have found that all NRG1 subtypes contain an EGF-like domain essential for regulating biological activities. The NRG1 needs to bind to the dimerized ErbB receptors to transmit the signaling from the extracellular to the intracellular space. First, the EGF-like domain binds to the tyrosine kinase receptor ErbB3 or ErbB4, which subsequently forms a heterodimer with ErbB2, an orphan receptor lack of a ligand-binding domain, as a co-receptor in signal transduction (Carraway and Cantley, 1994). The ErbB3 lacks an activated tyrosine kinase domain and it heterodimerically binds to either ErbB2 or ErbB4 for signal transduction. The ErbB4 can form a homodimer by itself, but it preferentially forms a heterodimer with ErbB2. They are both co-expressed on the cell surface, and transmit extracellular signals to activate the intracellular signaling pathways, including phosphatidylinositol-kinase 3-kinase $(\mathrm{PI} 3 \mathrm{~K}) /$ protein kinase $\mathrm{B}$ (PKB/Akt), mitogen-activated protein kinase (MAPK)/extracellular signal regulated kinases (ERK) and p38/MAPK, thus being involved in a variety of both physiological and pathophysiological processes (Calvo et al., 2011; Figure 2).

It has been proved that NRG1 precursors can be expressed predominately within cortical neurons, whereas soluble NRG1 accumulates preferentially on the surface of astrocytes of white matter. Research shows that NRG1 activity can also be detected in human cerebrospinal fluid, and its level seems to change in neuronal diseases. Although the level of NRG1 was found to be unchanged in the cerebrospinal fluid of patients with multiple sclerosis, it was found to be slightly reduced in that of ALS and PD patients, and significantly increased in that of AD patients (Pankonin et al., 2009). In addition, scientists have found that NRG1 is expressed in the gray matter, hypothalamus and cerebellum in the developing rat brain tissue. By comparison, NRG1 is abundantly expressed in developing brain tissues, including the hypothalamus, hippocampus, basal ganglia and brainstem (Bernstein et al., 2006; Figure 3). Some studies have shown that NRG1 and its receptors-ErbB4 are expressed in hypothalamic astrocytes, which can secret prostaglandin E2 under the stimulation of NRG1 in a paracrine manner, thus stimulating the release of luteinizing hormone releasing hormone (LHRH) and participating in sexual maturation (Bernstein et al., 2006). Recent studies have found that NRG1 can be expressed in pituitary gonadotrophin cells and phosphorylatively activate the prolactotroph surface receptors to promote the release of 


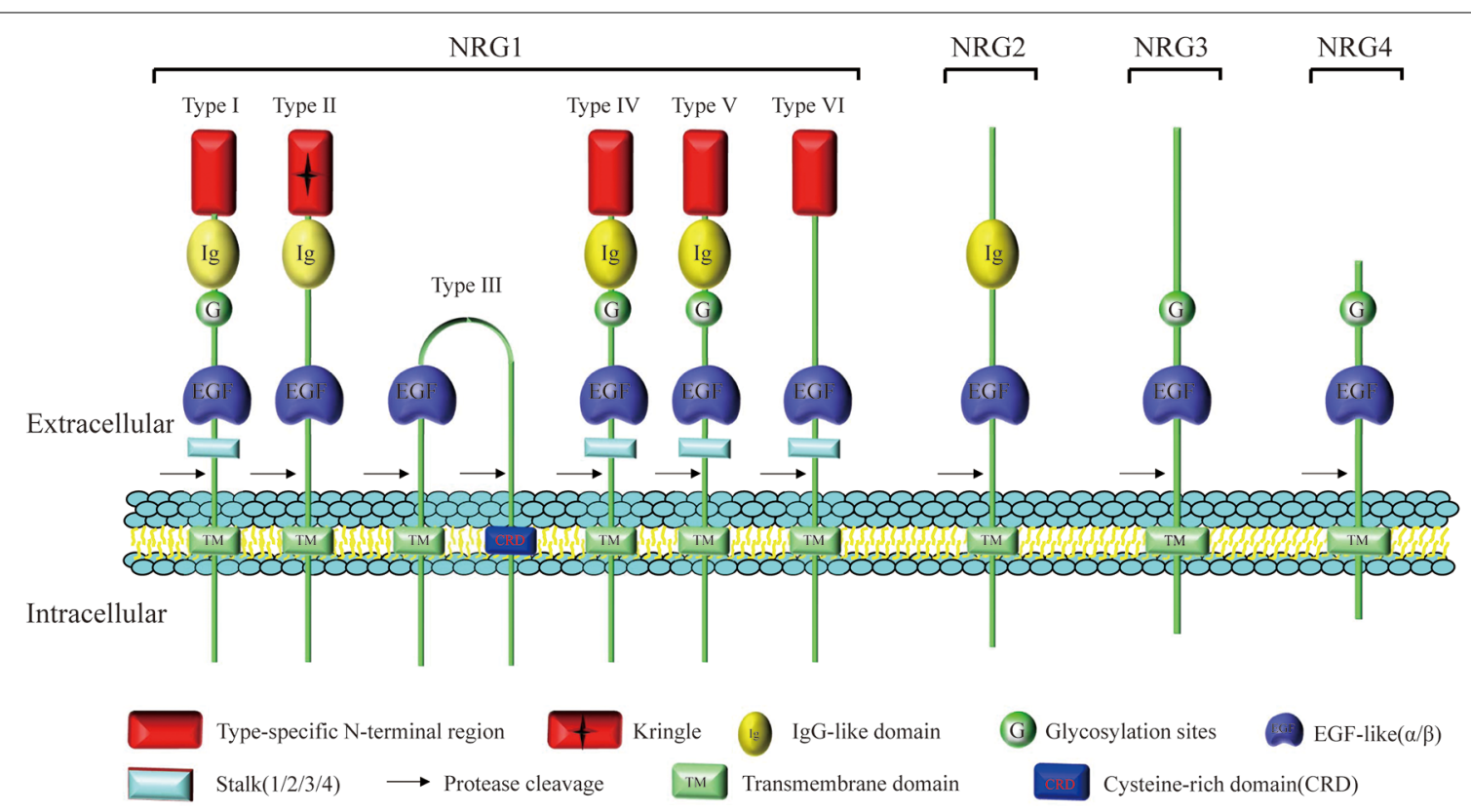

FIGURE 1 | Structure and homology of neuregulin (NRG). All NRG isoforms contain a fragment encoding an epidermal growth factor (EGF)-like domain which regulates the association of NRG ligands with the ErbB receptor tyrosine kinase family. Different splicing of NRG1 gene can produce at least six NRG1 (I-VI) subtypes characterized by different extracellular domains, but only types I, II, IV, and V contain the Ig-like domain. Type II NRG1 contains a GGF-specific ("Kringle") domain and type III NRG-1 contains a unique cysteine rich domain (CRD). NRG2 is most closely related to NRG1, and NRG1-3 exhibit high primary sequence homology, especially near the transmembrane (TM) domain. Compared with other NRGs containing multiple domains, such as the lg-like domain, cysteine-rich domain (CRD) or mucin-like domain, NRG4 does not contain these recognizable domains except the EGF-like domain.

prolactin in a juxtacrine manner (Zhao and Ren, 2011a,b; Zhao et al., 2011); and in vitro, NRG1 can also promote the invasion of breast cancer cells, regulate the actin cytoskeleton, and promote cancer cell metastasis in both autocrine or paracrine manners (Hijazi et al., 2000; Miller et al., 2006). Furthermore, the interaction between NRG1 and its receptors can activate ERK, Akt, MAPK, PI3K, PKC and JAK-STAT signaling molecules, leading to cell cycle changes, cell differentiation, initiation of anti-apoptotic processes and tumorigenesis (Peles et al., 1993; Lydia et al., 2002; Table 1).

\section{Structure, Distribution and Biological Functions of Neuregulin 2}

After the successful identification of NRG1 gene, the other three genes, NRG2 (Busfield et al., 1997; Carraway et al., 1997), NRG3 (Zhang et al., 1997) and NRG4 (Harari et al., 1999), which encode corresponding proteins, were successively found in later scientific studies. NRG2, also known as NTAK (neural-and thymus-derived activator for ErbB kinases), has been identified as the second member of the NRG family, with a similar structure to NRG1 (Busfield et al., 1997; Carraway et al., 1997; Figure 1). Although NRG1 and NRG2 are strongly expressed early in the developing brain, especially in the germinal layer, they are expressed in different brain tissue cell populations and distributed in different subcellular structures (Corfas et al., 1995; Longart et al., 2004). In the adult brain, the expression of NRG1 is generally decreased, scattered and widely distributed in the brain (Longart et al., 2004; Liu et al., 2011). In contrast, NRG2 is persistently expressed in three regions of the adult brain-cerebellum, olfactory bulb and hippocampal dentate gyrus (Carraway et al., 1997; Longart et al., 2004). Unlike NRG1 targeted to both axons and dendrites, NRG2 is concentrated in the dendrites of neurons (Longart et al., 2004; Figure 3). This unique temporal and spatial expression pattern of NRG2 suggests that it may have precised biological functions distinct from those of NRG1 (Yamada et al., 2000). Similar to NRG1, NRG2 transactivates ErbB1 and ErbB2 by directly binding to either ErbB3 or ErbB4, which can form a heterodimerized complex with them individually (Bublil and Yarden, 2007). Nakano et al. (2016) showed that NRG2 secreted by astrocytes can bind to ErbB3 receptor on neurons, promote neuronal survival and axon extension in vitro. This is similar to the role of NRG1 signaling pathway in glia-neuron interaction that promotes neuronal development, maturation and myelin formation (Fricker et al., 2011; Figure 4, Table 1).

\section{Structure, Distribution and Biological Functions of Neuregulin 3}

Neureguin3 (NRG3) was originally found in DNA sequence databases and DNA libraries when screening for genes with sequence similarities to members of the NRG1 family (Zhang et al., 1997). As another member of the EGF family protein ligand, NRG3 has 31\% homology with NRG1 in the amino acid sequence (Zhang et al., 1997). Some studies have found that the 


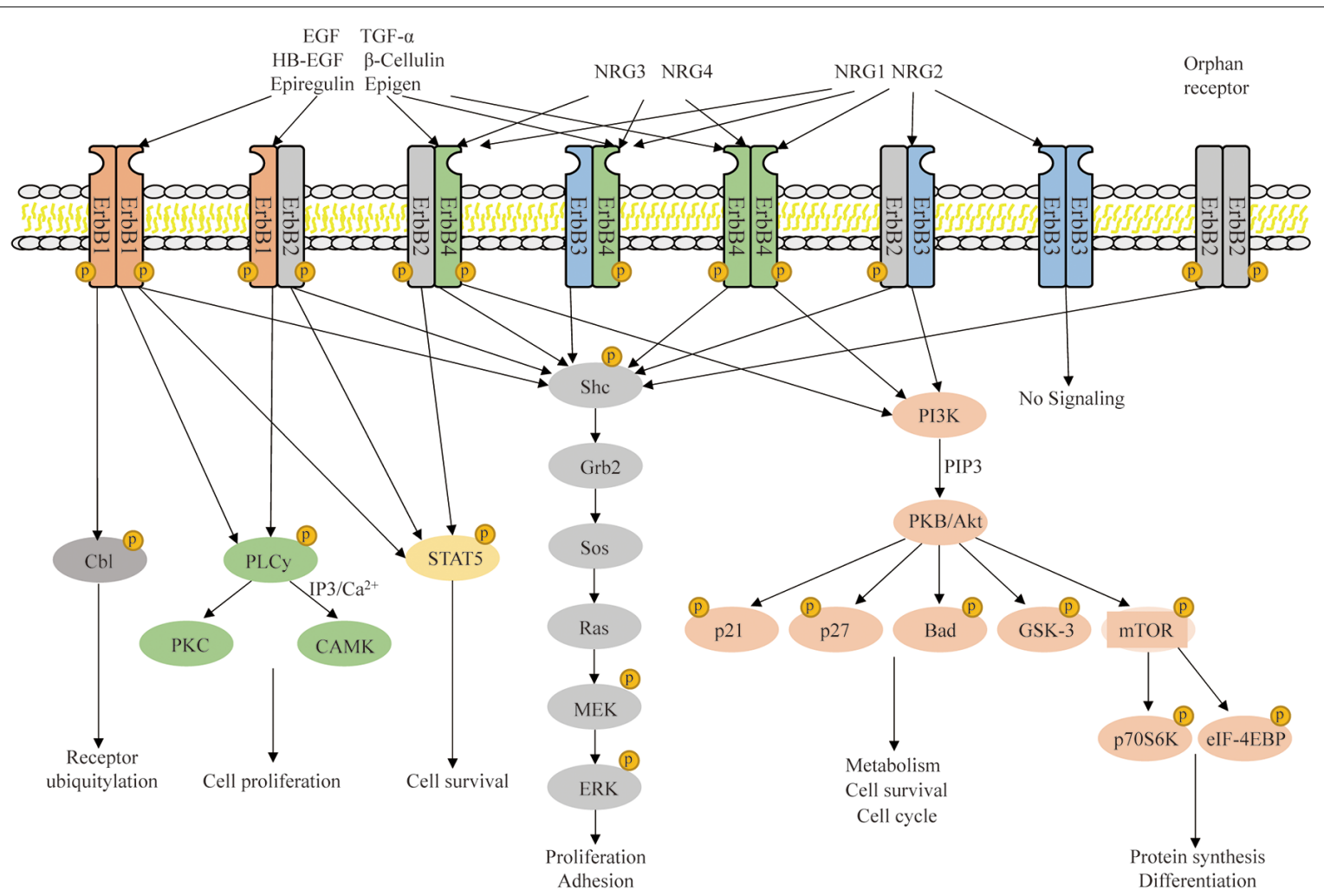

FIGURE 2 | NRG/ErbB signaling and downstream signaling pathway. The NRG1-4 ligand interaction with ErbB1-4 increases their affinity and induces homodimerization and heterodimerization of ErbB1-4, thus activating the tyrosine kinase domain and allowing the phosphorylated activation of ErbB receptorsin the cytoplasmic region. These processes regulate multiple intercellular signal transduction and participate in a wide range of biological processes in the nervous system.

\begin{tabular}{|c|c|c|c|c|c|c|c|c|}
\hline & NRG1 & NRG2 & NRG3 & NRG4 & ErbB1 & ErbB2 & ErbB3 & ErbB4 \\
\hline Astrocytes & + & - & + & + & + & + & + & + \\
\hline Microglia & - & - & - & - & - & - & + & + \\
\hline Oligodendrocytes & + & + & + & + & + & - & + & + \\
\hline OPC & - & + & + & - & + & - & + & + \\
\hline Neuron & + & + & + & + & + & + & + & + \\
\hline Pericytes & - & + & + & + & + & + & + & + \\
\hline Smooth muscle cell & + & + & - & + & + & + & - & + \\
\hline Vascular fibroblast-like cell & + & - & - & - & + & + & + & - \\
\hline Endothelial cell & + & + & + & + & + & + & + & + \\
\hline
\end{tabular}

FIGURE 3 | The expression level of NRGs and their ErbB receptors in the brain. "-" represents the absence or low level of expression, and "+" represents the presence or high level of expression in single cells (Zhang et al., 2014; He et al., 2018; Xu et al., 2018). OPC, oligodendrocyte precursor cell.

N-terminal domain of NRG3 is similar to SMDF (Ho et al., 1995), lacking Ig-like and spacer domains contained in most members of NRG1 family. Although some studies have predicted that the extracellular domain of NRG3 may lack common sites for $\mathrm{N}$-linked glycosylation, some potential O-linked glycosylation sites have been found, and the similarity between the intracellular domain of NRG3 and that of NRG1 is very limited (Zhang et al., 1997; Figure 1). Scientists have proved that NRG3 is expressed in both embryonic and postnatal nervous systems (Zhang et al., 1997), including the important region adjacent to the rostral migratory stream (RMS; Stavroula et al., 2003; Anton et al., 2004). As a specific ligand of receptor tyrosine kinase 
TABLE 1 | Related binding receptors, major molecular function and biological process involved in neuregulins (NRGs).

\begin{tabular}{|c|c|c|c|}
\hline Neuregulin & Receptor & Molecular function & Biological process \\
\hline \multirow[t]{12}{*}{ NRG1 } & $\begin{array}{l}\text { ErbB3 } \\
\text { ErbB4 }\end{array}$ & Growth factor activity (Lee et al., 2001) & $\begin{array}{l}\text { Negative regulation of transcription (Zhang and Hamburger, } \\
\text { 2004); }\end{array}$ \\
\hline & & Transmembrane receptor protein tyrosine & Negative regulation of neuron migration (Pan and \\
\hline & & kinase activator activity (Zhao et al., 1998); & Dobrowsky, 2013); \\
\hline & & $\begin{array}{l}\text { Transcription coregulator activity (Zhang and } \\
\text { Hamburger, 2004); }\end{array}$ & $\begin{array}{l}\text { Positive regulation of peptidyl-tyrosine autophosphorylation } \\
\text { (Fleisig et al., 2004); }\end{array}$ \\
\hline & & Cytokine activity (Osheroff et al., 1999); & $\begin{array}{l}\text { Neurotransmitter receptor metabolic process } \\
\text { (Rahimi-Aliabadi et al., 2017); }\end{array}$ \\
\hline & & Chemorepellent activity (Gaudet et al., 2011); & Myelination in peripheral nervous system (Britsch, 2007); \\
\hline & & $\begin{array}{l}\text { ErbB-2/3 class receptor binding (leguchi et al., } \\
\text { 2010) }\end{array}$ & Glial cell differentiation (Kataria et al., 2019); \\
\hline & & & Neural crest cell development (Britsch, 2007); \\
\hline & & & Intracellular signal transduction (Gaudet et al., 2011); \\
\hline & & & Activation of MAPK activity (leguchi et al., 2010); \\
\hline & & & ErbB signaling pathway (leguchi et al., 2010); \\
\hline & & & $\begin{array}{l}\text { Cellular protein complex disassembly (Trinidad and Cohen, } \\
\text { 2004) }\end{array}$ \\
\hline \multirow[t]{8}{*}{ NRG2 } & ErbB3 & Growth factor activity (Lee et al., 2015); & ErbB2 signaling pathway (Hobbs et al., 2004); \\
\hline & ErbB4 & & \\
\hline & & Transmembrane receptor protein tyrosine & Nervous system development (Yarden, 2001); \\
\hline & & kinase activator activity (Hobbs et al., 2004); & \\
\hline & & & MAPK cascade (Brown and Sacks, 2009); \\
\hline & & Signaling receptor binding (Chang et al., 1997) & \\
\hline & & & $\begin{array}{l}\text { Positive regulation of protein kinase B signaling (Burke et al., } \\
\text { 2011); }\end{array}$ \\
\hline & & & Intracellular signal transduction (Gaudet et al., 2011) \\
\hline \multirow[t]{6}{*}{ NRG3 } & ErbB4 & Growth factor activity (Zhang et al., 1997); & Intracellular signal transduction (Gaudet et al., 2011); \\
\hline & & Transmembrane receptor protein tyrosine & Nervous system development (Yarden, 2001); \\
\hline & & kinase activator activity (Zhang et al., 1997); & \\
\hline & & Chemorepellent activity (Gaudet et al., 2011); & Regulation of cell growth (Zhang et al., 1997); \\
\hline & & Signaling receptor binding (Gaudet et al., 2011) & \\
\hline & & & $\begin{array}{l}\text { Modulation of chemical synaptic transmission (Zhou et al., } \\
\text { 2018) }\end{array}$ \\
\hline \multirow[t]{7}{*}{ rtNRG4 } & ErbB4 & Growth factor activity (Pfeifer, 2015); & $\begin{array}{l}\text { Nervous system development (Buonanno and Fischbach, } \\
\text { 2001); }\end{array}$ \\
\hline & & Transmembrane receptor protein tyrosine & MAPK cascade (Brown and Sacks, 2009); \\
\hline & & kinase activator activity (Schumacher et al., & \\
\hline & & 2017); & $\begin{array}{l}\text { Positive regulation of protein kinase B signaling (Mandelker } \\
\text { et al., 2009); }\end{array}$ \\
\hline & & Signaling receptor binding (Harari et al., 1999); & \\
\hline & & & Regulation of cell motility (Marone et al., 2004) \\
\hline & & Protein binding (Luck et al., 2020) & \\
\hline
\end{tabular}

ErbB4, the structure and polymorphism of NRG3 are associated with neurodevelopmental disorders, including developmental retardation, cognitive impairment, autism and schizophrenia (Meier et al., 2013). Intriguingly, however, NRG3 can also bind to ErbB4, thus synergistically affecting proliferation, migration and differentiation of neuroblasts as a paralog of NRG1 (Table 1).

\section{Structure, Distribution and Biological Functions of Neuregulin 4}

Neuregulin4 (NRG4) was originally detected in adult pancreas and muscle and was initially identified as a necessary factor for tissue growth (Harari et al., 1999). Further studies have shown that NRG4 is also present in human breast 


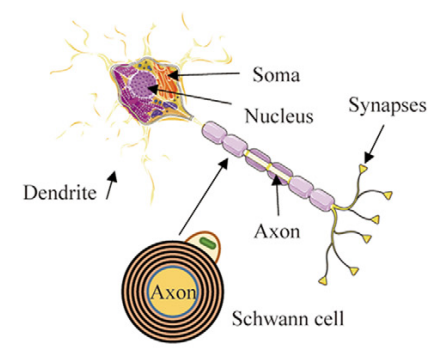

Regulation of development, maturation and myelination of Schwann cell

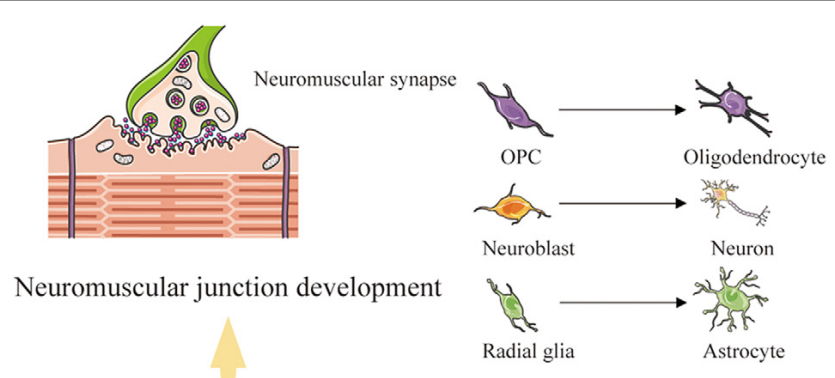

Neural cells differentiation

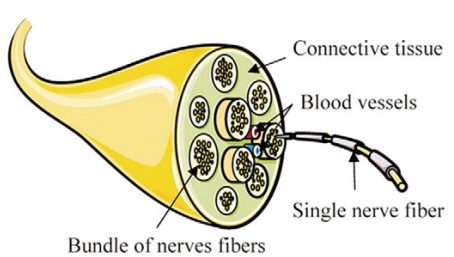

Recover neurological function after nerve injury

FIGURE 4 | Diverse roles of NRG/ErbB signaling in the nervous system. Through the interaction with the ErbB-family receptors to increase phosphorylation on tyrosine residues, NRG family member proteins can induce the growth, proliferation and differentiation of epithelial, neuronal and glial cells, and potentially other types of cells. Furthermore, NRGs are involved in neuromuscular junction development, repair after nerve injury, synapse formation, and regulation of glutamate, GABA and dopamine release.

milk and growing intestinal tissue, where it promotes the survival of epithelial cells and prevents the necrosis of intestinal cells (Bernard et al., 2012; McElroy et al., 2014). In addition, studies have shown that NRG4 is highly expressed in prostate cancer, breast cancer, and gastric cancer (Hayes et al., 2010; Mariana et al., 2010; Nielsen et al., 2014).

As a homologous ligand of the EGF/NRG family, NRG4 has very low sequence homology with known members of the NRG family besides the EGF-like domain (Harari et al., 1999). In contrast, the other three NRGs (NRG1-3) exhibit high primary sequence homology especially near the transmembrane domain (Harari et al., 1999). It has been found that the precursor form of NRG4 has the same structural characteristics as an ErbB ligand in mammals (Massagué and Pandiella, 1993), including the transmembrane domain, EGF-like domain proximal to the membrane, and the proteolytic cleavage site in the serine-rich region at the C-terminus of EGF-like domain (Harari et al., 1999). Besides the two potential N-linked glycosylation sites in the known extracellular domain of NRG4, the ectodomain region also contains the O-linked glycosylation site (Harari et al., 1999). Although NRG4 lacks hydrophobic signal peptide for $\mathrm{N}$-terminal localization, like other NRGs, it is different from the most EGFR specific ligands (Falls, 2003; Figure 1). However, the absence of these sequence characteristics does not rule out the possibility that NRG4 can be secreted as a growth factor, in that, other growth factors without a signal peptide, can be secreted or released from cells by alternative secretion mechanisms or autolysis (Burden and Yarde, 1997). In addition, NRG4 lacks non-polar amino acids (Harari et al., 1999), which usually replace the signal peptide. And the hypothetical extracellular domain of NRG4 is the shortest among members of the NRG/EGF family (Harari et al., 1999). Unlike other NRGs, the NRG4 does not contain the recognizable domains, such as the Ig-like domain, cysteine-rich domain (CRD) and mucin-like domain, except the EGF-like domain (Harari et al., 1999; Table 1).

\section{NEUREGULINS IN THE DEVELOPMENT AND THERAPEUTICS OF NEURODEGENERATIVE DISEASES}

\section{Neuregulins and AD}

Alzheimer's disease (AD) is a neurodegenerative disease with insidious and progressive onset, mainly in the elderly, and its incidence increases with age (Masters et al., 2015). As a disease entity, $\mathrm{AD}$ shares many characteristics with other molecularly defined neurodegenerative diseases including PD and frontotemporal dementia (FTD). It is therefore deduced that $\mathrm{AD}$ is the result of abnormal aging, which increases the risk of $\mathrm{AD}$. In the most clinical aspects, the sporadic and familial forms of $\mathrm{AD}$ are comparable, including the rate of disease progression and biomarker profiles (Chang et al., 2016). A recent study 
(Talboom et al., 2019) found that memory loss may indicate an early sign of a severe problem in a young person with a family history of AD.

Alzheimer's disease (AD) is a continuously progressive disease clinically characterized by changes in cognition or behavior (Gallucci et al., 2008; Masters et al., 2015). First, mild symptoms are mainly caused by memory loss, but life can still be maintained by self-care. Second, moderate symptoms are characterized by memory decline, obvious cognitive defects, and disorientation in time and place, and the patients have to be supported to take care of their life. Finally, severe symptoms are characterized by severe mental decline, and the patients are unable to carry out outdoor activities independently and they cannot take care of their life themselves. During the progression of the disease, the patients may also experience changes in mood and personality. They may experience abnormal mood swings, such as agitation, irritability, impulsivity, lack of motivation, apathy and paralysis (Goedert and Spillantini, 2006).

Alzheimer's disease (AD) is pathologically characterized mainly by: (1) senile plaque formed by abnormal deposition of $\beta$-amyloid protein outside neurons; and (2) NFTs formed by abnormal phosphorylation of tau protein (Masters et al., 2015). Recent studies have shown that abnormal phosphorylation of tau protein is more highly correlated with $\mathrm{AD}$ than abnormal deposition of $\beta$-amyloid protein. A large amount of abnormally aggregated tau protein exists in the brain of $\mathrm{AD}$ patients. Abnormal modification and content change of tau protein play an important role in the clinicopathogenesis of $\mathrm{AD}$ (Bussian et al., 2018).

According to the 2018 Alzheimer's Clinical Trials Report conducted by Alzheimer's Drug Discovery Foundation (ADDF) (Alzheimer's Drug Discovery Foundation, 2019), the drug treatment effect on $\mathrm{AD}$ is very limited, while research on pharmacology has not yet developed effective drugs to treat $\mathrm{AD}$, only offering symptomatic relief. Currently, the pathogenesis of $\mathrm{AD}$ is not clear due to the complicated cause of the disease, which has comprised the main dilemma of new drug research and development. Regarding the cause of $\mathrm{AD}$, the mainstream view is still a series of insults caused by abnormal aggregation of $\beta$-amyloid $(A \beta)$ and hyperphosphorylation of tau protein (Grundke-Iqbal et al., 1986; Arriagada et al., 1992; Carson and Turner, 2002). Scientists have carried out many drug screening tests, animal trials, clinical research and other experimental work targeting these two major pathogenesis mechanisms. In the past 20 years, drug research and development have focused on clearance of the $A \beta$ plaques in the brain (Morimoto, 2010), but most of the alternatives have not been successful. The therapeutic effect of available drugs against $\mathrm{AD}$ is relatively limited, and there is no efficient way to stop the progression of the disease (Masters et al., 2015). At present, the anti-AD drugs used clinically are medically attributed to "neurotransmitter therapeutic drugs," and the effects are obtained by changing the concentration or intensity of neurotransmitters in the brain of AD patients (Hara et al., 2019). For instance, the mainstream anti-AD drug, cholinesterase inhibitor, can increase in the brain the concentration of acetylcholine and improve cognition, whose absence has been considered a potential cause of AD.

\section{Neuregulin 1 and $A D$}

As cell-to-cell signaling proteins that are ligands for receptor tyrosine kinases of the ErbB receptor family (Falls, 2003), NRGs and their corresponding receptors play pivotal roles in organ development and maintenance, as well as in many disorders (Gallucci et al., 2008; Cespedes et al., 2018; Yan et al., 2018; Kataria et al., 2019). The NRG1 has been originally reported to be associated with schizophrenia (Harrison and Law, 2006) and has been implicated in neuro developmental processes including neuronal differentiation and synapse formation (Buonanno and Fischbach, 2001). NRG1 can promote neurite outgrowth in hippocampal and thalamic primary neurons (Gerecke et al., 2004), and even can attenuate cognitive function impairments in AD mice (Ryu et al., 2016). Jiang et al. (2016) suggested that NRG1 may serve as a preventive agentby influencing the pathological development of AD. Woo et al. (2011) discovered that both ErbB4 and phospho-ErbB4 immunoreactive intensities were higher in neurons of the CA1-2 transitional field of $\mathrm{AD}$ brains as compared to age-matched normal controls. ErbB4 expression was increased in the neurons of the corticomedial amygdala nucleus, human basal forebrain, as well as those of the superior frontal gyrus of $\mathrm{AD}$. In the cerebral cortex and hippocampus of amyloid precursor protein (APP)/presenilin 1 (APP/PS1) double transgenic mice, ErbB4 immunoreactivity is significantly increased compared with the age-matched wild type control. These combined reports indicated that the abnormal change of ErbB4 may be involved in the progression of $\mathrm{AD}$ pathology and NRG1 can undertake neuroprotective actions against Swedish amyloid precursor protein-induced neurotoxicity (Woo et al., 2011; Table 2).

In addition to the $\mathrm{A} \beta$ peptide, other metabolites of amyloid precursor protein (APP) such as the C-terminal fragments of APP (APP-CTs) have been reported to exert cytotoxic effects in neuronal cells (Baik et al., 2016). Ryu et al. (2012) investigated whether NRG1 exerts neuroprotective effects against APP-CTs and attempted to determine the underlying neuroprotective mechanisms. Their results

TABLE 2 | Differential expression of NRGs and their ErbB receptors in Alzheimer's disease (AD) brain (vs. normal brain; Xu et al., 2018; Zhang et al., 2019).

\begin{tabular}{|c|c|c|c|c|c|c|c|c|}
\hline & NRG1 & NRG2 & NRG3 & NRG4 & ERBB1 & ERBB2 & ERBB3 & ERBB4 \\
\hline Entorhinal cortex & * & NA & $* * *$ & ns & $* * *$ & $* * *$ & ** & * \\
\hline Hippocampus & ns & ns & * & ns & $\star *$ & ns & ns & ns \\
\hline Temporal cortex & * & * & NA & ns & * & ns & * & ns \\
\hline Frontal cortex & ns & $\star *$ & NA & NA & ns & ns & * & ns \\
\hline
\end{tabular}

ns, $P$-value $>0.05 ;{ }^{*}$-value $<0.05 ;{ }^{* *} P$-value $<0.01 ;{ }^{* * *} P$-value $<0.001 ; N A$, not available. 
showed that NRG1 alleviates the neurotoxicity induced by the expression of APP-CTs in neuronal cells. NRG1 also reduces the accumulation of reactive oxygen species and attenuates mitochondrial membrane potential loss induced by APP-CTs, which can be blocked by ErbB4 inhibition (Ryu et al., 2012).

NRG1 exerts pivotal functions in both brain development and plasticity, as well as in neuroprotection (Ryu et al., 2012; Willem, 2016; Xu et al., 2017). Another research (Baik et al., 2016) focused on the downstream signaling pathways of NRG1 and their roles in the prevention of A $\beta 42$-induced neurotoxicity, demonstrating that inhibition of PI3K/Akt activation abolished the ability of NRG1 to prevent $\mathrm{A} \beta 42$-induced $\mathrm{LDH}$ release and increase the counting numbers of TUNEL-positive cells and reactive oxygen species (ROS) accumulation in primary cortical neurons. These studies further confirm that NRG1 signaling exerts a neuroprotective effect against $\mathrm{A} \beta 42$-induced neurotoxicity via activation of the PI3K/Akt signaling pathway, with a neuroprotective potential for the treatment of $\mathrm{AD}$ (Baik et al., 2016; Figure 5).

In the nervous system, the functions of NRG1 are essential for peripheral myelination, the establishment and maintenance of neuromuscular and sensorimotor systems and the plasticity of cortical neuronal circuits (Cespedes et al., 2018). It has been reported that intracerebroventricular infusion of NRG1 attenuated cognitive impairments in a 13month-old Tg2576 AD mouse model (Ryu et al., 2016). In addition, NRG1 can rescue the reduction in the Golgi-Cox staining-based counting number of dendritic spines in the brain of Tg2576 mice (Ryu et al., 2016). The NRG1 also alleviated the decrease in neural differentiation induced by oligomeric $\mathrm{A} \beta 1-42$ in mouse fetal neural stem cells with therapeutic potential for $\mathrm{AD}$ by alleviating the reduction in dendritic spine density and neurogenesis found in the AD brain (Ryu et al., 2016). The NRG1 regulates neuronal survival, synaptogenesis, astrocytic differentiation, and microglial activation, thus being involved in the development of the nervous system. Research has demonstrated the expression and distribution of NRG1 and ErbB kinases in the hippocampus of $\mathrm{AD}$ patients and in transgenic mice co-expressing $\mathrm{AD}$-associated mutations of $\beta$ amyloid precursor protein (APPK670N, M671L) and presenilin-1 (PS1M146L; Chaudhury et al., 2003). NRG1 and its three ErbB receptors (ErbB2, ErbB3 and ErbB4) are expressed in distinct cellular compartments of neurons in the hippocampi of both control humans and wild type mice. In the $\mathrm{AD}$ brain, upregulated NRG1 was found in both microglia, and to a less extent dystrophic neurites in neuritic plaques, suggesting that both autocrine and paracrine interactions can regulate the action of NRG1 within these lesions. It can thus be inferred that NRG1 and ErbB4, as well as ErbB2, are similarly associated with neuritic plaques in the APP/PS1 transgenic mice (Chaudhury et al., 2003; Table 3).

Inhibition of the protease $\beta$-site amyloid precursor proteincleaving enzyme 1 (BACE1) represents a potential treatment for $\mathrm{AD}$, and lots of $\mathrm{BACE}$ inhibitors are progressing through clinical trials at present (Munro et al., 2016). BACE was first identified

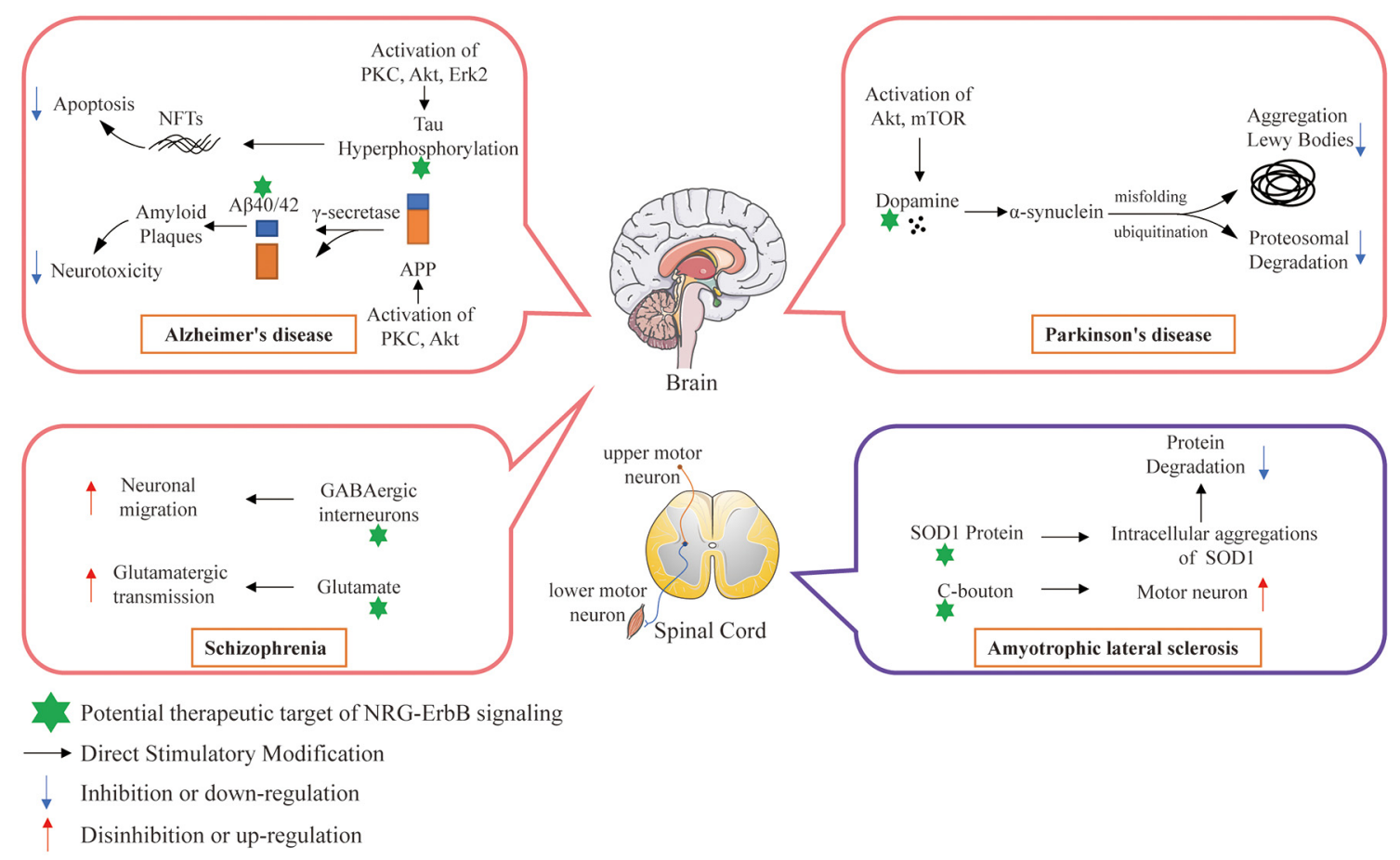

FIGURE 5 | Potential therapeutic targets of NRG/ErbB signaling involved in selected neurodegenerative diseases. 
TABLE 3 | Convergent functional genomic (CFG) ranking for NRGs and their ErbB receptors in AD (Xu et al., 2018; Zhang et al., 2019).

\begin{tabular}{|c|c|c|c|c|c|c|}
\hline & \multirow[t]{2}{*}{ eQTL } & \multirow[t]{2}{*}{ GWAS } & \multirow[t]{2}{*}{ PPI } & \multicolumn{2}{|c|}{ Pathology } & \multirow[t]{2}{*}{ CFG } \\
\hline & & & & $\mathbf{A} \boldsymbol{\beta}$ & Tau & \\
\hline NRG1 & 2 & 21 & PSEN1, APOE & $-0.118 \mathrm{~ns}$ & $-0.614^{*}$ & 5 \\
\hline NRG2 & 3 & 7 & PSEN1 & NA & NA & 3 \\
\hline NRG3 & 3 & 1 & PSEN1 & $-0.378^{*}$ & $-0.357^{\mathrm{ns}}$ & 4 \\
\hline NRG4 & 2 & 0 & PSEN1 & $0.002^{\mathrm{ns}}$ & $-0.106^{\mathrm{ns}}$ & 2 \\
\hline ErbB1 & 2 & 2 & PSEN1, PSEN2, APOE & $0.119^{\text {ns }}$ & $0.012^{\text {ns }}$ & 3 \\
\hline ErbB2 & 3 & 0 & PSEN1, PSEN2, MAPT & NA & NA & 2 \\
\hline ErbB3 & 1 & 0 & APP, PSEN1, MAPT & NA & NA & 2 \\
\hline ErbB4 & 4 & 0 & PSEN1, PSEN2 & NA & NA & 2 \\
\hline
\end{tabular}

eQTL: expression of target gene is regulated by AD genetic variants (genetic variants: IGAP GWAS P-value < 1E-3; eQTL: P-value < 1E-3); GWAS: IGAP P-value < 1E-3; PPI: target gene has significant physical interaction with APP, PSEN1, PSEN2, APOE or MAPT (P-value < 0.05); Pathology (A $\beta$ ): correlation of target gene expression with AD pathology in A $\beta$ line $A D$ mouse models (r, $P$-value; ${ }^{n s} P$-value $>0.05$; ${ }^{*}$-value < 0.05 ; NA, not available; Pathology (Tau): correlation of target gene expression with $A D$ pathology in tau line $A D$ mouse models (r, P-value; ${ }^{n s} P$-value > 0.05; * $P$-value <0.05; NA, not available; CFG: total CFG score of target gene. One CFG point is added if any of above evidence is significant, CFG point ranges from zero to five. CFG ranks is an approach integrating multiple lines of evidence, for example, genetic association, PPI, gene expression alteration, and pathology correlation, to prioritize $A D$ candidate genes.

through its function as the rate limiting enzyme of amyloid$\beta$ peptide $(A \beta)$ production. Scientists have aimed to reduce the production of amyloid- $\beta$ (A $\beta$ ) peptide from the amyloid precursor protein (APP) to reduce or prevent $A \beta$ toxicity (Ryu et al., 2012; Masters et al., 2015; Cespedes et al., 2018). Over the last decade, it has become clear that BACE1 proteolytically cleaves several substrates in addition to APP. These substrates are not only known to be involved in the pathogenesis of $\mathrm{AD}$, but have other roles in the developing and/or mature CNS (Munro et al., 2016). Among BACE1 substrates that have been validated to date, some may contribute to the synaptic deficits resulting from BACE blockade, including NRG1, close homolog of L1 and seizure-related proteins (Munro et al., 2016; Chen et al., 2017). NRG1 was identified as a major physiological substrate of BACE1 during early postnatal development when phenotyping similarities between BACE1 KO mice and NRG1 heterozygous mice. Due to its hairpin nature, type IIINRG1 is subjected to a secondary cleavage by BACE1 to release the EGF-like domain on the basis of the initial proteolytic cleavage (Willem, 2016). Thus, it is important to understand the possible role of blocking the effects of BACE on NRG1, as well as other proteins detected in substrate screening, and to develop substrate-selective BACE inhibitors against $\mathrm{AD}$.

Some recent research suggests that NRG1 signaling is of great importance in cognitive function and neuropathology in $\mathrm{AD}$ (Ryu et al., 2016; Cespedes et al., 2018; Talboom et al., 2019). Xu et al. (2016) overexpressed full-length type I or type III NRG1 via lentiviral vectors in the hippocampus of line $41 \mathrm{AD}$ mouse. They found that both type I and type III NRG1 can improve memory deficits scored by the Morris water-maze behavioral task, accompanied by neuropathological ameliorations (Xu et al., 2016). Consistent with the result of increased neprilysin (NEP) immunoreactivity in the hippocampus of $\mathrm{AD}$ mice, the study also showed that soluble ectodomains of type $I$ and type III NRG1s significantly increased expression of $A \beta$-degrading enzyme NEP in primary neuronal cultures (Xu et al., 2016). Furthermore, Chang et al. (2016) found that plasma soluble NRG1 (sNRG1) is among the biomarkers for AD diagnosis. They investigated a potential difference in the level of the plasma proteins between $60 \mathrm{AD}$ patients and 55 healthy subjects. Their research showed that the level of sNRG1 was significantly higher both in mild $\mathrm{AD}$ and in moderate $\mathrm{AD}$ patients compared with that of the normal control subjects (Chang et al., 2016).

Although ErbB4 is expressed in multiple regions of the adult animal brain, findings on its role in $\mathrm{AD}$ are still limited. Research shows that ErbB4 immunoreactivity is significantly increased in apoptotic hippocampal pyramidal neurons in the brain of $\mathrm{AD}$ patients, where it is co-localized with the apoptotic signaling molecule Bax. Thisobservation suggests that up-regulation of ErbB4 immunoreactivity in apoptotic neurons may involve in the pathological progression of $\mathrm{AD}$ (Woo et al., 2011). In the brain, from both $\mathrm{AD}$ patients and that from the APP/PS1 transgenic AD mouse, ErbB4 can be expressed by reactive astrocytes and microglia surrounding the neuritic plaques. In $\mathrm{AD}$ brains, NRG1 is up-regulated in microglia, dystrophic neurites, and in neuritic plaques, indicating that NRG1-based autocrine and/or paracrine interactions exist within these lesions (Chaudhury et al., 2003).

NRG1, ErbB4 and ErbB2 are similarly associated with neuritic plaques in the APP/PS1 transgenic AD mouse. It has been reported that the hippocampal distribution of NRG1 and ErbB4 was altered in AD (Chaudhury et al., 2003; Table 2). Also, scientists inactivated ErbB2/ErbB4-mediated NRG1 signaling specifically in the CNS by CRE/LOX technology (Barros et al., 2009). Although they found that cortical layers develop normally in the cerebral cortex, hippocampus, and cerebellum, the loss of ErbB2/ErbB4 functions influences dendritic spine maturation and disturbs the interaction between postsynaptic scaffold proteins and glutamate receptors, and ErbB2/ErbB4 receptorsdeficient mice exhibit enhanced aggression and lower prepulse inhibition (Barros et al., 2009). Further research found that in APP/PS1 transgenic mice, NRG1 $\beta 1$ antagonizes neuronal apoptosis via ErbB4-dependent activation of PI3-kinase/Akt. The extracellular domain of NRG1 $\beta 1$ (NRG1 $\beta 1$-ECD) increase the levels of pErbB4 receptor and pAkt, and increase the level of $\mathrm{Bcl}-2$ both in in vitro studies and APP/PS1 transgenic mice (Cui et al., 2013). Riethmacher et al. (1997) found that both sensory and motor neurons require factors like CNTF, GDNF, BDNF, LIF, PDFG, FGF, NT-3 or TGF- $\beta$ for survival, development, 
maintenance and regeneration provided by developing Schwann cells. Taveggia et al. (2005) found ensheathment fate of axons can be determined by NRG1 type III, which is the sole NRG1 isoform retained at the axon surface to activates PI3-kinase for Schwann cell myelination. Meanwhile, in ErbB3 mutant embryos, most motor neurons and sensory neurons in dorsal root ganglia undergo cell death at later stages, indicating that ErbB3 functions in a cell-autonomous way during the development of Schwann cells, but not in the survival of sensory or motor neurons (Riethmacher et al., 1997; Figure 5).

\section{Neuregulin 2 and AD}

As a member of the epidermal growth factor (EGF) family, NRG2 can bind directly to ErbB3 and ErbB4, thus transactivating ErbB2 (Nakano et al., 2004). Although research has demonstrated that NRG1 can promote axonal regeneration and play a neuroprotective role in neurodegenerative diseases (Ryu et al., 2012; Mancuso et al., 2016; Xu et al., 2016), it remains unclear about the biological functions and related mechanisms of NRG2 in neurodegenerative diseases, especially in $\mathrm{AD}$. Researchers observed that NRG2 $\beta$ is a potent agonist for ErbB4 receptor. However, NRG2 $\alpha$, which is derived from the splicing isoform of the same gene also encoding NRG2 $\beta$, is an inefficient ErbB4 agonist (Hobbs et al., 2004). Studies showed that the substitution of a lysine residue for Phe45 in $\mathrm{NRG} 2 \beta$ results in a reduced ligand potency, and substitution of a phenylalanine for Lys45 in NRG2 $\alpha$ enhances the ligand potency (Hobbs et al., 2004).

Nakano et al. (2016) showed that NRG2 secreted by astrocytes binds to ErbB3 receptor on neurons and promotes neuronal survival and axonal extension in vitro, which is similar to the role of NRG1 in the CNS development, maturation and myelin formation of glial-neuron interactions. After analysis of the regional and temporal expression of NRG1-3 and comparison of the processing and subcellular distribution of NRG2 with NRG1 proteins, Longart et al. (2004) found that NRG2 is developmentally regulated and targeted to dendrites of central neurons. To further investigate the roles of NRG2 in synaptogenesis and dendritic growth, Lee et al. (2015) depleted NRG2 at different developmental stages of newborn GCs with a tetracycline-inducible expression system, showing that dual roles of NRG2 in the newborn neurons.
The extracellular domain of NRG2 mediates synaptogenesis by binding ErbB4 receptor on GABAergic neurons via forward signaling pathways. In contrast, the intracellular domain of NRG2 contributes to dendritic outgrowth and glutamatergic synapse maturation via reverse signaling pathways (Lee et al., 2015). Vullhorst et al. (2015) also confirmed that NRG2 can bi-directionally bind NMDA and ErbB4 receptors in the cortical GABAergic interneurons involved in glutamatergic transmission. Considering that neuronal development is a critical process of brain development, adult neurogenesis enhancement by NRG2 may represent a therapeutic strategy against both age and disease-related neuronal loss.Although there is no direct evidence to prove the effect of NRG2 in the treatment of AD, its potential cannot be ignored.

\section{Neuregulin 3 and $A D$}

Neuregulin (NRG3), a specific ligand for ErbB4 and a neuronalenriched neurotrophin, has been identified as a protein structurally related to the NRG1. It is involved in the genetic predisposition to a broad spectrum of neurodevelopmental, neurocognitive and neuropsychiatric disorders, including $\mathrm{AD}$, autism and schizophrenia (Gallucci et al., 2008; Paterson and Law, 2014; Wang K.-S. et al., 2014; Table 4). It plays an important role in neuronal development, including plasticity, development, differentiation, and proliferation (Zhou et al., 2020).

The genetic studies have suggested that ErbB4 activation may also be regulated in the CNS by NRG3 (Zhang et al., 1997). Although knowledge of the genetic involvement of NRG3 in neurological diseases has been vastly expanded, little is known about its roles in the risk mechanisms of the development of neurodegenerative diseases (Meier et al., 2013; Loos et al., 2014; Wang K.-S. et al., 2014). Paterson and Law (2014) found that developmental overexposure to NRG1 induced multiple non-CNS mediated peripheral effects and severely disrupted the performance of prepulse inhibition of the startle response. In contrast, NRG3 exerts no effects on any peripheral measures investigated or on sensorimotor gating. In particular, developmental NRG3 overexposure even produced an anxiogenic-like phenotype and deficits in social behavior in adulthood, indicating that NRG3 plays an important role in brain

TABLE 4 | Overview of selected neurodegenerative diseases.

\begin{tabular}{|c|c|c|c|c|c|}
\hline Diseases & $\begin{array}{l}\text { Clinical } \\
\text { characteristics }\end{array}$ & Neuropathology & Lesion site & Protein & $\begin{array}{l}\text { Associated } \\
\text { NRGs }\end{array}$ \\
\hline Alzheimer's disease & $\begin{array}{l}\text { Cognitive and memory } \\
\text { impairment }\end{array}$ & $\begin{array}{l}\text { Neurofibrillary tangles } \\
\text { (NFTs); } \\
\text { Amyloid plaques }\end{array}$ & $\begin{array}{l}\text { Hippocampus; } \\
\text { Cerebral cortex }\end{array}$ & $\begin{array}{l}\text { Microtubule-associated } \\
\text { proteintau (tau); } \\
\text { Amyloid- } \beta \text { (A } \beta \text { ) }\end{array}$ & NRG1; NRG3 \\
\hline Parkinson's disease & $\begin{array}{l}\text { Rest tremor; } \\
\text { Rigidity; } \\
\text { Bradykinesia }\end{array}$ & $\begin{array}{l}\text { Damage of dopaminergic } \\
\text { neurons; } \\
\text { Formation of Lewy bodies }\end{array}$ & $\begin{array}{l}\text { Substantia nigra; } \\
\text { Hypothalamus }\end{array}$ & $\alpha$-Synuclein & NRG1 \\
\hline $\begin{array}{l}\text { Amyotrophic lateral } \\
\text { sclerosis }\end{array}$ & $\begin{array}{l}\text { Dysphagia; } \\
\text { Partial muscle stiffness; } \\
\text { Dyskinesia }\end{array}$ & $\begin{array}{l}\text { Upper and lower motor } \\
\text { neuron loss; } \\
\text { Bunina bodies; } \\
\text { Astrocytic hyaline inclusions }\end{array}$ & $\begin{array}{l}\text { Motor cortex; } \\
\text { Brain stem }\end{array}$ & $\begin{array}{l}\text { Superoxide dismutase } \\
1 \text { (SOD1) }\end{array}$ & NRG1 \\
\hline Schizophrenia & $\begin{array}{l}\text { Perception, thinking, } \\
\text { emotion and behavior } \\
\text { disorientations }\end{array}$ & $\begin{array}{l}\text { Dyssecretion of dopamine } \\
\text { and 5-hydroxytryptamine }\end{array}$ & Cerebral cortex & $\begin{array}{l}\text { Dysbindin; } \\
\text { Ubiquitin }\end{array}$ & $\begin{array}{l}\text { NRG1; NRG2 } \\
\text { NRG3; NRG4 }\end{array}$ \\
\hline
\end{tabular}


development and function, appearing to be distinct from NRG1 (Paterson and Law, 2014).

NRG3 gene at $10 \mathrm{q} 22-\mathrm{q} 24$ has been implicated in multiple psychiatric traits such as cognitive impairment (Meier et al., 2013). To discover the role of the NRG3 gene polymorphism in $\mathrm{AD}$, scientists explored the relationship between $N R G 3$ and age-of-onset of $\mathrm{AD}(\mathrm{AAO})$ and the risk of $\mathrm{AD}$ development (Wang K.-S. et al., 2014). By logistic regression and linear regression analyses, secondary data analysis of 257 singlenucleotide polymorphisms (SNPs) in NRG3 was performed in $806 \mathrm{AD}$ patients and 782 controls. Using an independent familybased sample, scientists found one SNP rs11192423 associated with AAO both in the case-control sample $(p=0.0155)$ and in the family sample $(p=0.0166)$, indicating that genetic variants in the NRG3 gene play a role in $\mathrm{AD}$ and SNPs in the NRG3 genes and were more strongly associated with $\mathrm{AAO}$ of $\mathrm{AD}$ (Wang K.-S. et al., 2014).

Recent research found that NRG3 and ErbB4 are located at presynaptic and postsynaptic structures, respectively, in excitatory synapses on parvalbumin-positive interneurons. And the ablation of NRG3 can lead to a similar phenotype to that of ErbB4 ablation, including reduced excitatory synapse numbers on parvalbumin-positive interneurons, altered short-term plasticity, and disinhibition of the hippocampal network. Further investigation demonstrated that presynaptic NRG3 increases excitatory synapse numbers and affects short-term plasticity of ErbB4-positive interneurons. These results indicate that NRG3 can promote excitatory synapse formation of hippocampal interneurons and can play a crucial role in synaptogenesis and synapse functions (Müller et al., 2018).

\section{Neuregulin 4 and AD}

Studies have shown that the extracellular fragment with the EGF-like domain produced by NRG4 proteolysis usually acts on target cells to exert their functions in the form of autocrine, paracrine or juxtacrine manner (Hayes et al., 2010; Mariana et al., 2010; Nielsen et al., 2014). In the meantime, more and more research has found that NRG4 plays an important role in controlling energy balance, increasing insulin sensitivity and reducing the development of fatty liver (Wang G.-X. et al., 2014; Dai et al., 2015).

Through analysis of NRG4-deficient mice, Paramo et al. (2018) found that both the apical and basal dendrites of neocortical pyramidal neurons are significantly stunted in NRG4-/- neonates in vivo compared to NRG4+/+ littermates, and recombinant NRG4 rescued the stunted phenotype of embryonic neocortical pyramidal neurons cultured from NRG4-/- mice. However, they observed that the pyramidal dendrite arbors of NRG4 $-/-$ and NRG4+/+ mice were similar in the adult, demonstrating compensatory changes that occur in the pyramidal dendrites of NRG4-/- mice with age. The majority of cultured NRG4+/+ mice embryonic cortical pyramidal neurons co-express NRG4 and its receptor ErbB4 (Paramo et al., 2018). These results show that NRG4 serves as a major physiologically relevant regulator of the growth and elaboration of pyramidal neuronal dendrites in the developing neocortex. Meanwhile, Paramo et al. (2019) found that NRG4 can also function as a significantly novel regulator of dendritic growth and arborization and spine formation in the striatum, exerting its effects by an autocrine/paracrine mechanism (Paramo et al., 2019). Meanwhile, NRG4 can act directly on striatal medium spiny neurons during development in vivo (Paramo et al., 2019). These studies showed that NRG4 has a crucial function in the developing brain. Thus, it will be interesting to ascertain how the putative NRG4/ErbB4 autocrine loop is regulated in pyramidal neurons and investigate how NRG4 contributes to the pathogenesis of particular neurodegenerative diseases such as AD.

\section{Neuregulins in Other Neurodegenerative Diseases \\ Neuregulins in Parkinson's Disease (PD)}

Parkinson's disease (PD) follows $\mathrm{AD}$ as the second severe neurodegenerative disease (Reitz et al., 2011), with morbidity of more than $1 \%$ in people above the age of 60 years, $5 \%$ in people above the age of 65 years, and $20 \%$ in people above the age of 80 years old (Bloodsworth et al., 2000; Przedborski, 2017). The clinical manifestations of PD are mainly characterized by resting muscle tremors, myotonia, retardation of movement, postural reflex disorder, and other motor neuronal dysfunctions (Li et al., 2017; Przedborski, 2017). In addition, some patients also suffer from abnormal autonomic nervous system functions, such as cognitive impairment, autonomic nerve dysfunctions and etc. (Caligiore et al., 2016; Malek et al., 2017). The main pathological features of PD patients were the damage and loss of dopaminergic neurons in the compact part of substantia nigra (SN), the decrease of dopamine levels in the striatum and the formation of Lewy bodies in the cytoplasm of residual neurons (Irene et al., 2012; Table 4). Studies have shown that the decrease of striatal dopamine levels can lead to the decrease of dopamine innervations in the SN-striatal pathway, the relative enhancement of cholinergic nerve functions and the occurrence of motor dysfunctions in PD patients (Irene et al., 2012; Figure 5).

At present, it is believed that the etiology of PD is mainly related to age, environment and genetic factors (Caligiore et al., 2016). In the meantime, more than ten PD-related genes have been found, among which the most common ones are LRRK2, $\alpha$-synuclein, PINK1, DJ-1, Parkin and others (Chou and Kah-Leong, 2013), thus providing some basis for further studying the molecular mechanism of PD. Despite intensive drug development, symptomatic treatment is still the main therapeutic method clinically. The commonly used drugs include dopamine analogs and anticholinergics, but there is no specific cure for PD.

In the past decade, researchers came to pay attention to the role of NRGs in PD, to identify strategies to cure or alleviate PD. Carlsson et al. (2011) studied the effect of systemic administration of NRG1 $\beta 1$ on dopaminergic neurons in a mouse model of PD, and they found that dopamine levels were increased in $\mathrm{SN}$ and striatum of the treated adult mouse. NRG1 $\beta 1-\mathrm{ECD}$ also significantly protected the mouse nigrostriatal dopaminergic system against 6-hydroxydopamine (6-OHDA)-induced toxicity both morphologically and functionally in vivo, and protected human dopaminergic neurons against 6-OHDA in vitro. In 
another 1-methyl-4-phenyl-1,2,3,6-tetrahydropyridine (MPTP) toxin-based mouse model of $\mathrm{PD}$, researchers also found that systematic administration of NRG1 $\beta 1-E C D$ can rescue nigral dopaminergic neurons via the ErbB4 receptor tyrosine kinase (Depboylu et al., 2015). However, NRG1ß1-ECD cannot reverse MPTP-induced decrease in dopamine levels and dopaminergic fibers in the striatum. In addition, NRG1 $\beta 1$-ECD cannot affect the conversion of MPTP to its toxic metabolite 1-methyl-4-phenylpyridinium (MPP) as well as levels of the dopamine transporter to influence the intracellular uptake of MPP (Depboylu et al., 2015). In addition, they also found that ErbB4 is upregulated in midbrain dopaminergic neurons in PD, which may reflect a better survival of ErbB4-positive neurons or an increased expression of ErbB4 by residual neurons to pursue neurotrophic support (Depboylu et al., 2013). Hama et al. (2015) found that the level of plasma type III NRG1 is reduced and is specifically associated with idiopathic PD, although its correlation with the clinical severity of PD has not been confirmed. Thus, NRG1 type III reduction may facilitate the etiological diagnosis of PD.

\section{Neuregulins in Amyotrophic Lateral Sclerosis (ALS)}

Amyotrophic lateral sclerosis (ALS), also known as motor neuron disease (MND) or Lou Gehrig's disease, is a disease that causes the death of neurons controlling voluntary muscles (Lee and Kim, 2015). It is characterized by the degeneration of both upper and lower motor neurons and leads to muscle weakness and eventual paralysis (Hardiman et al., 2017). Except for the familial/genetic susceptibility, the etiology of ALS remains unknown in most patients. Although the main symptoms of ALS are related to motor dysfunction (such as muscle weakness, cramps, and dysphagia), upto $50 \%$ of patients experience cognitive and/or behavioral disorders during the disease procession. $13 \%$ of patients present with concomitant behavioral variant prontotemporal dementia (FTD; Neumann et al., 2006; Phukan et al., 2012; Elamin et al., 2013), which contributes to the recharacterization of ALS as a neurodegenerative rather than a neuromuscular disorder and points out the direction of future research (Table 4).

In a recent study on the relationship between ErbB4 and ALS/FTD, ErbB4 mutation was found for the first time in ALS/FTD and that its mutation reduced auto-phosphorylation of upon NRG1 stimulation (Sun et al., 2020). Song et al. (2012) analyzed the relationship between NRG1 isoform expression and glial cell activation and motor neuron loss in the spinal cord of ALS patients during the disease progression in a superoxide dismutase 1 (SOD1)-mutated ALS mouse model. They observed microgliosis, astrocytosis, and motor neuron loss in the ventral horn of ALS patients, and these symptoms increased as the disease progressed in the model. The expression of membrane-tethered type III NRG1 decreased in parallel with the motor neuronal loss, while secretory type I NRG1 expression increased, which was related to the activation of glial cells. In addition, enhanced activation of NRG1 receptor was observed in activated microglia in both ALS patients and the SOD1-mutated ALS mouse model (Song et al., 2012). Coincidentally, another research team also found that NRG1 confers neuroprotection in SOD1-linked ALS mice via the restoration of C-boutons (the large cholinergic synapses that innervate spinal $\alpha$-motor neurons to control their excitability) of spinal motor neurons (Lasiene et al., 2016). In addition, their research also found that the loss of NRG1 expression and C-boutons occurred almost contemporaneously and the expressions of ErbB3 and ErbB4 were reduced in the motor neurons of SOD1-muted ALS mice. Mòdol-Caballero et al. (2020) also found that NRG1 expression was reduced in both ALS patients and the SOD1-mutated ALS mouse model. Overexpression of type III NRG1 can preserve the neuromuscular function of the hindlimbs, improve locomotor performance, increase the number of surviving motoneurons, and reduce glial reactivity in the treated female SOD1 mice. However, it shows no therapeutic efficiency mentioned above in male mice, indicating a possible gender difference. These studies suggest that disruption of the NRG1/ErbB4 pathway is associated with the pathogenesis of ALS and may develop an innovative therapeutic strategy, such as the use of NRGs or their analogs to enhance the function of ErbB4 (Figure 5).

\section{Neuregulins in Schizophrenia}

Schizophrenia is one of the serious psychiatric diseases whose etiology is not fully elucidated. The main clinical characteristics of schizophrenia are perception, thinking, emotion and behavioral disorientations (Owen et al., 2016; Table 4). Although the exact pathogenesis of schizophrenia has not been clarified, it is commonly believed that the pathogenesis and development process of schizophrenia are controlled by genetic and environmental factors. Related studies have found that many common psychiatric diseases have a high genetic tendency and are related to some candidate risk genes, such as schizophrenia (Fusar-Poli et al., 2007), anxiety (Domschke and Dannlowski, 2010), depression (Inkster et al., 2010) and mood disorders (Scharinger et al., 2010). A recent study suggests that some cases of schizophrenia may be associated with abnormal protein accumulation in the brain, similar to $\mathrm{AD}$ and other neurodegenerative diseases (Nucifora et al., 2019). Researchers examined postmortem brain samples from 42 schizophrenic subjects and found that half of the brain samples contained significantly higher levels of abnormal proteins, as well as elevated levels of ubiquitin, which is considered as a marker of protein aggregates in neurodegenerative diseases (Ardley and Robinson, 2004; Nucifora et al., 2019).

Studies suggest that NRG1/ErbB4 interactions play a vital role in the pathological mechanism of schizophrenia (Li et al., 2006). With the development of molecular genetics, many genes are related to schizophrenia (Harrison and Weinberger, 2005), of which the most supportive gene is NRG1 (Harrison and Weinberger, 2005; Norton et al., 2006; Li B. et al., 2007). Thus, the link between the genetic variation of NRGs and the increased risk of schizophrenia development may be determined by the wide-ranging effects of NRGs on brain functions (Wang et al., 2009).

The direct and chronic disturbance of NRG1/ErbB4 signal transmission, such as the mutation of NRG1 or ErbB4 gene 
in some schizophrenia patients (Walss-Bass et al., 2006), can lead to the abnormality of glutamatergic synapses and nerve fibers, thus leading to developmental and functional abnormalities. However, the mutation of genes NRG1 or ErbB4 may only account for a small part of schizophrenia cases (Harrison and Weinberger, 2005). Other signal transduction or structural components in glutamatergic pathway may be defective, resulting in low function, and may result in the compensatory increase of NRG1/ErbB4 expression and activation levels (Li B. et al., 2007). Dang et al. (2016) investigated the expression of NRG1 and phosphorylated activation status of ErbB4 and ErbB2 in the prefrontal cortex of rats following chronic administration of antipsychotics such as haloperidol, risperidone and clozapine, demonstrating enhanced NRG1/ErbB signaling in the brain. Moreover, studies have found that NRG1 has an important effect on the differentiation, migration and maturation of $\gamma$ aminobutyric acid (GABA) interneurons (Flames et al., 2004; Díez et al., 2014). GABA is an important inhibitory neurotransmitter in the forebrain of mammals. It can inhibit intermediate neurons and is essential for the normal function of the CNS (McBain and Fisahn, 2001). GABA dysfunction involves several neurological diseases, including schizophrenia (Coyle, 2004; Woo et al., 2007; Figure 5). In addition, the synaptic hypothesis about the underlying pathophysiological mechanism of schizophrenia suggests that the dysfunction of glutamatergic system can causally affect the onset of schizophrenia (Coyle and Tsai, 2004; Harrison, 2004; Harrison and Weinberger, 2005). In humans, reducing glutamatergic transmission can mimic schizophrenia symptoms (Pietraszek, 2003), whereas, increasing glutamatergic transmission can reduce schizophrenia symptoms (Javitt, 2004). Schizophrenia patients showthe decreased excitatory synaptic function in the hippocampus and cortex (Abbott and Bustillo, 2006; Gan et al., 2014). Another important feature of schizophrenia is neurodevelopmental abnormality. In the early developmental stage, schizophrenia-like symptoms appear in animals with destroyed fiber connection between hippocampus and frontal cortex (Bertolino et al., 1997; Lipska, 2004; Raper et al., 2014). Human studies have shown that early brain maturation, such as premature delivery or perinatal brain injury, may lead to schizophrenia (Pantelis et al., 2005; Rehn and Rees, 2005). These data integratively indicate that the core features of schizophrenia, such as genetic defects, developmental abnormalities and glutamatergic neuron dysfunction, are interrelated (Figure 5).

In order to reveal the role of NRG2 in the modulation of behaviors with relevance to psychiatric disorders, Vullhorst et al. (2015) found a negative feedback loop between N-methylD-aspartate receptors (NMDARs) and NRG2/ErbB4 signaling in GABAergic interneurons. Meanwhile, Yan et al. (2018) investigated the role of NRG2 in dopamine balance and glutamatergic transmission using NRG2 knockout mice, and they found NRG2 knockout mice show higher extracellular dopamine levels in the dorsal striatum but lower levels in the medial prefrontal cortex, and NMDAR synaptic currents are augmented at hippocampal glutamatergic synapses. Although the direct evidence of the role of NRG2 in the etiology of schizophrenia remains to be determined, the findings of NRG2 on neuropsychiatric disorders are still inspiring. In addition, NGR3 variants are more associated with the disease manifestations (especially delusions), which appear to be mediated by quantitative changes in the alternative splicing of the gene consistently (Stefansson et al., 2002). Genetic research in schizophrenia shows that risk variants in NRG3 are associated with cognitive and psychotic symptom severity, which is accompanied by increased expression of prefrontal cortical NRG3 (Meier et al., 2013). While the function and processing of NRG3 have not been studied as well as its NRG1 homolog, their overlaps in similarity and function allow researchers to identify the roles of NRG3 identical to those of NRG1 in schizophrenia (Fiona et al., 2010). Fallin et al. (2005) reported the association of SNP rs1080293 within the gene associated with schizophrenia in a study of 64 candidate genes, including NRG3. In addition, Benzel et al. (2007) investigated the interaction between SNP genotypes across components of the NRG-ErbB signaling network, and they discovered disease-associated SNPs in ErbB4, NRG1, NRG2, NRG3 and ErbB1, as well as significant evidence of interaction between NRG3 and NRG1. Visibly, NRG3 follows NRG1 into the spotlight of schizophrenia research, showing that the influence of genetic variation may exert on the specificity of a phenotype in addition to the risk for this disease.

\section{CONCLUSION AND FUTURE PERSPECTIVES}

Although scientists are looking forward to finding cures for neurodegenerative diseases with complex and unclear pathogenesis, no comprehensive and effective treatments and drugs have been developed. The results of a growing number of studies suggest that NRG1 regulates cell maintenance, differentiation, proliferation, migration, and survival or apoptosis in both neuronal and nonneuronal cell types (Mei and Xiong, 2008). Research on NRGs and their corresponding receptors in both invertebrate and vertebrate models, including Drosophila (Hidalgo et al., 2001), zebrafish (Brown et al., 2017), mouse (Kato et al., 2009), rat (Zhao et al., 2015) and even non-human primate rhesus monkey (Zhao, 2013b), have shown their complex involvement in the development of the nervous system and related diseases.

Current evidence has indicated that NRGs play important roles in neurological disorders such as brain trauma (Fricker et al., 2013) and cerebrovascular diseases (Li Y. et al., 2007), and neurodegeneration-related disorders such as AD (Chang et al., 2016), PD (Carlsson et al., 2011), schizophrenia (Mostaid et al., 2016) and ALS (Liu et al., 2018). At present, the clinical translational research on modulation of NRG-ErbB receptor signaling mainly focuses on the targeted treatment of cancers, such as human breast cancer (Geyer et al., 2006; Hurvitz et al., 2013), colorectal cancer (Yonesaka et al., 2011) and gastric cancer (Sato et al., 2013). However, most of these treatments are based on inhibition of NRG-ErbB receptor signaling (Geyer et al., 2006). Good tolerability has been reported 
for short-termsystemic administration of recombinant human NRG1 (rhNRG1) in a phase II clinical trial (Gao et al., 2010), supporting the potential translation of NRG-ErbB receptor signaling enhancement in the treatment of neurodegenerative diseases. In spite of this, the uncertain CNS penetrant degree may constitute one of the obstacles impeding the application of recombinant rhNRG. An increasing number of studies have inspiringly used virtual screening techniques to obtain small molecule compounds that may potentially treat $\mathrm{AD}$ and $\mathrm{PD}$ by targeting key pathogenic proteins (Shinde et al., 2015; Gancia et al., 2017; Patel et al., 2018). Thus, future investigation may focus on sound CNS-penetrant small molecule compounds as NRG substitutes to modulate ErbB receptor signaling in the translational treatment of neurodegenerative diseases.

In order to strengthen the understanding of NRGs in neurodegenerative disease prevention and treatment, further relevant mechanisms need to be clarified in the future. More in-depth future research on NRGs is necessary to improve diagnostic solutions for neurodegenerative diseases, thereby reducing the burden on both patients and families.

\section{REFERENCES}

Abbott, C., and Bustillo, J. (2006). What have we learned from proton magnetic resonance spectroscopy about schizophrenia? A critical update. Curr. Opin. Psychiatry 19, 135-139. doi: 10.1097/01.yco.0000214337.29378.cd

Alzheimer's Drug Discovery Foundation. (2019). 2018 Alzheimer's Clinical Trials Report. Available online at: https://www.alzdiscovery.org/research-andgrants/clinical-trials-report/2018-report.

Anton, E. S., Ghashghaei, H. T., Weber, J. L., McCann, C., Fischer, T. M., Cheung, I. D., et al. (2004). Receptor tyrosine kinase ErbB4 modulates neuroblast migration and placement in the adult forebrain. Nat. Neurosci. 7 , 1319-1328. doi: 10.1038/nn1345

Ardley, H. C., and Robinson, P. A. (2004). The role of ubiquitin-protein ligases in neurodegenerative disease. Neurodegener. Dis. 1, 71-87. doi: $10.1159 / 000080048$

Arriagada, P. V., Marzloff, K., and Hyman, B. T. (1992). Distribution of Alzheimer-type pathologic changes in nondemented elderly individuals matches the pattern in Alzheimer's disease. Neurology 42, 1681-1688. doi: $10.1212 /$ wnl.42.9.1681

Baik, T.-K., Kim, Y.-J., Kang, S.-M., Song, D.-Y., Min, S. S., and Woo, R. S. (2016). Blocking the phosphatidylinositol 3-kinase pathway inhibits neuregulin-1mediated rescue of neurotoxicity induced by A $\beta 1-42$. J. Pharm. Pharmacol. 68, 1021-1029. doi: 10.1111/jphp. 12563

Bao, S., Wu, Q., McLendon, R. E., Hao, Y., Shi, Q., Hjelmeland, A. B., et al. (2006). Glioma stem cells promote radioresistance by preferential activation of the DNA damage response. Nature 444, 756-760. doi: 10.1038/nature 05236

Barnham, K. J., Masters, C. L., and Bush, A. I. (2004). Neurodegenerative diseases and oxidative stress. Nat. Rev. Drug Discov. 3, 205-214. doi: 10.1038/ $\operatorname{nrd} 1330$

Barros, C. S., Barbara, C., Pablo, C., Roberts, A. J., Ed, K., Kent, L., et al. (2009). Impaired maturation of dendritic spines without disorganization of cortical cell layers in mice lacking NRG1/ErbB signaling in the central nervous system. Proc. Natl. Acad. Sci. U S A 106, 4507-4512 doi: 10.1073/pnas.09003 55106

Bartus, K., Galino, J., James, N. D., Hernandez-Miranda, L. R., Dawes, J. M., Fricker, F. R., et al. (2016). Neuregulin-1 controls an endogenous repair mechanism after spinal cord injury. Brain 139, 1394-1416. doi: 10.1093/brain/aww039

Bateman, R. (2015). Alzheimer's disease and other dementias: advances in 2014. Lancet Neurol. 14, 4-6. doi: 10.1016/S1474-4422(14)70301-1

\section{AUTHOR CONTRIBUTIONS}

$\mathrm{W}-\mathrm{jZ}$ : conceptualization. $\mathrm{W}-\mathrm{jZ}, \mathrm{G}-\mathrm{yO}$, and $\mathrm{W}-\mathrm{wL}$ : writing-original draft preparation. $\mathrm{W}-\mathrm{jZ}$ and $\mathrm{G}-\mathrm{yO}$ : writing-review and editing.

\section{FUNDING}

This work was supported by the National Natural Science Foundation of China (81471279 and 81171138 to $\mathrm{W}-\mathrm{jZ}$ ), Research start-up fund of Jiangnan University (1285081903200020 to W-jZ), and Research start-up fund of Wuxi School of Medicine, Jiangnan University (1286010242190060 to $\mathrm{W}-\mathrm{jZ} Z$ ).

\section{ACKNOWLEDGMENTS}

We thank the reviewers whose constructive comments and suggestions have helped improve the quality of our manuscript.

Baulida, J., Kraus, M. H., Alimandi, M., Fiore, P. P. D., and Carpenter, G. (1996). All ErbB receptors other than the epidermal growth factor receptor are endocytosis impaired. J. Biol. Chem. 271, 5251-5257. doi: 10.1074/jbc.271. 9.5251

Benzel, I., Bansal, A., Browning, B. L., Galwey, N. W., Maycox, P. R., McGinnis, R., et al. (2007). Interactions among genes in the ErbB-Neuregulin signalling network are associated with increased susceptibility to schizophrenia. Behav. Brain Funct. 3:31. doi: 10.1186/1744-9081-3-31

Bernard, J. K., McCann, S. P., Bhardwaj, V., Washington, M. K., and Frey, M. R. (2012). Neuregulin-4 is a survival factor for colon epithelial cells both in culture and in vivo. J. Biol. Chem. 287, 39850-39858. doi: 10.1074/jbc.M112. 400846

Bernstein, H.-G., Lendeckel, U., Bertram, I., Bukowska, A., Kanakis, K., Dobrowolny, H., et al. (2006). Localization of neuregulin-1 $\alpha$ (heregulin- $\alpha$ ) and one of its receptors, ErbB-4 tyrosine kinase, in developing and adult human brain. Brain Res. Bull. 69, 546-559. doi: 10.1016/j.brainresbull.2006. 02.017

Bertolino, A., Saunders, R. C., Mattay, V. S., Bachevalier, J., Frank, J. A., and Weinberger, D. R. (1997). Altered development of prefrontal neurons in rhesus monkeys with neonatal mesial temporo-limbic lesions: a proton magnetic resonance spectroscopic imaging study. Cereb. Cortex 7, 740-748. doi: 10.1093/cercor/7.8.740

Bhat, A. H., Dar, K. B., Anees, S., Zargar, M. A., Masood, A., and Sofi, M. A. (2015). Oxidative stress, mitochondrial dysfunction and neurodegenerative diseases; a mechanistic insight. Pharmacotherapy 74, 101-110. doi: 10.1016/j.biopha.2015. 07.025

Bloodsworth, A., O’Donnell, V. B., Freeman, B. A., and Biology, V. (2000). Nitric oxide regulation of free radical- and enzyme-mediated lipid and lipoprotein oxidation. Arterioscler. Thromb. Vasc. Biol. 20:1707. doi: 10.1161/01.atv.20. 7.1707

Boland, D. F., and Mark, S. (2012). The economic and quality of life burden associated with Parkinson's disease: a focus on symptoms. Am. J. Manag. Care $18,168-175$.

Britsch, S. (2007). The neuregulin-I/ErbB signaling system in development and disease. Adv. Anat. Embryol. Cell Biol. 190, 1-65.

Brockes, J. P. (1983). Glial growth factor-a new component of the brain and pituitary. Birth Defects Orig. Artic. Ser. 19, 277-285.

Brown, M. D., and Sacks, D. B. (2009). Protein scaffolds in MAP kinase signalling. Cell Signal. 21, 462-469. doi: 10.1016/j.cellsig.2008.11.013

Brown, D., Samsa, L. A., Ito, C., Ma, H., Batres, K., and Arnaout, R. (2017). Neuregulin-1 is essential for nerve plexus formation during 
cardiac maturation. Mol. Med. 22, 2007-2017. doi: 10.1111/jcmm. 13408

Bublil, E. M., and Yarden, Y. (2007). The EGF receptor family: spearheading a merger of signaling and therapeutics. Curr. Opin. Cell Biol. 19, 124-134. doi: 10.1016/j.ceb.2007.02.008

Buonanno, A., and Fischbach, G. D. (2001). Neuregulin and ErbB receptor signaling pathways in the nervous system. Curr. Opin. Neurobiol. 11, 287-296. doi: 10.1016/s0959-4388(00)00210-5

Burden, S., and Yarde, Y. (1997). Neuregulins and their receptors: a versatile signaling module in organogenesis and oncogenesis. Neuron 18, 847-855. doi: 10.1016/s0896-6273(00)80324-4

Burke, J. E., Vadas, O., Berndt, A., Finegan, T., Perisic, O., and Williams, R. L. (2011). Dynamics of the phosphoinositide 3-kinase p1108 interaction with p $85 \alpha$ and membranes reveals aspects of regulation distinct from p110 $\alpha$. Structure 19, 1127-1137. doi: 10.1016/j.str.2011.06.003

Busfield, S. J., Michnick, D. A., Chickering, T. W., Revett, T. L., Ma, J., Woolf, E. A., et al. (1997). Characterization of a neuregulin-related gene, Don-1, that is highly expressed in restricted regions of the cerebellum and hippocampus. Mol. Cell. Biol. 17, 4007-4014. doi: 10.1128/mcb.17.7.4007

Bussian, T. J., Aziz, A., Meyer, C. F., Swenson, B. L., van Deursen, J. M., and Baker, D. J. (2018). Clearance of senescent glial cells prevents tau-dependent pathology and cognitive decline. Nature 562, 578-582. doi: 10.1038/s41586018-0543-y

Caligiore, D., Helmich, R. C., Hallett, M., Moustafa, A. A., Timmermann, L., Toni, I., et al. (2016). Parkinson's disease as a system-level disorder. NPJ Parkinsons Dis. 2:16025. doi: 10.1038/npjparkd.2016.25

Calvo, M., Zhu, N., Grist, J., Ma, Z., Loeb, J. A., and Bennett, D. L. H. (2011). Following nerve injury neuregulin-1 drives microglial proliferation and neuropathic pain via the MEK/ERK pathway. Glia 59, 554-568. doi: 10.1002/glia.21124

Calvo, M., Zhu, N., Tsantoulas, C., Ma, Z., Grist, J., Loeb, J. A., et al. (2010). Neuregulin-ErbB signaling promotes microglial proliferation and chemotaxis contributing to microgliosis and pain after peripheral nerve injury. J. Neurosci. 30, 5437-5450. doi: 10.1523/JNEUROSCI.5169-09.2010

Carlsson, T., Schindler, F. R., Höllerhage, M., Depboylu, C., Arias-Carrion, O., Schnurrbusch, S., et al. (2011). Systemic administration of neuregulin$1 \beta 1$ protects dopaminergic neurons in a mouse model of Parkinson's disease. J. Neurochem. 117, 1066-1074. doi: 10.1111/j.1471-4159.2011. 07284.x

Carraway, K. L. III., and Cantley, L. C. (1994). A neu acquaintance for erbB3 and erbB4: a role for receptor heterodimerization in growth signaling. Cell 78, 5-8. doi: 10.1016/0092-8674(94)90564-9

Carraway, K. L. III., Weber, J. L., Unger, M. J., Ledesma, J., Yu, N., Gassmann, M., et al. (1997). Neuregulin-2, a new ligand of ErbB3/ErbB4-receptor tyrosine kinases. Nature 387, 512-516. doi: 10.1038/387512a0

Carson, J. A., and Turner, A. J. (2002). $\beta$-amyloid catabolism: roles for neprilysin (NEP) and other metallopeptidases? J. Neurochem. 81, 1-8. doi: 10.1046/j.14714159.2002.00855.x

Cespedes, J. C., Liu, M., Harbuzariu, A., Nti, A., Onyekaba, J., Cespedes, H. W., et al. (2018). Neuregulin in health and disease. Int. J. Brain Disord. Treat. 4:024. doi: $10.23937 / 2469-5866 / 1410024$

Chang, H., Riese, D. J. II., Gilbert, W., Stern, D. F., and McMahan, U. J. (1997). Ligands for ErbB-family receptors encoded by a neuregulin-like gene. Nature 387, 509-512. doi: 10.1038/387509a0

Chang, K.-A., Shin, K. Y., Nam, E., Lee, Y.-B., Moon, C., Suh, Y. H., et al. (2016). Plasma soluble neuregulin-1 as a diagnostic biomarker for Alzheimer's disease. Neurochem. Int. 97, 1-7. doi: 10.1016/j.neuint.2016.04.012

Chaudhury, A. R., Gerecke, K. M., Wyss, J. M., Morgan, D. G., Gordon, M. N., and Carroll, S. L. (2003). Neuregulin-1 and erbB4 immunoreactivity is associated with neuritic plaques in Alzheimer disease brain and in a transgenic model of Alzheimer disease. J. Neuropathol. Exp. Neurol. 62, 42-54. doi: 10.1093/jnen/ 62.1 .42

Chen, G.-F., Xu, T.-H., Yan, Y., Zhou, Y.-R., Jiang, Y., Melcher, K., et al. (2017). Amyloid $\beta$ : structure, biology and structure-based therapeutic development. Acta Pharmacol. Sin. 38, 1205-1235. doi: 10.1038/aps.2017.28

Chou, C., and Kah-Leong, L. J. (2013). Genetic insights into sporadic Parkinson's disease pathogenesis. Curr. Genomics 14, 486-501. doi: $10.2174 / 1389202914666131210195808$
Corfas, G., Rosen, K. M., Aratake, H., Krauss, R., and Fischbach, G. D. (1995). Differential expression of ARIA isoforms in the rat brain. Neuron 14, 103-115. doi: 10.1016/0896-6273(95)90244-9

Costa, A., Peppe, A., Dell'Agnello, G., Caltagirone, C., and Carlesimo, G. A. (2009). Dopamine and cognitive functioning in de novo subjects with Parkinson's disease: effects of pramipexole and pergolide on working memory. Neuropsychologia 47, 1374-1381. doi: 10.1016/j.neuropsychologia.2009.01.039

Coyle, J. T. (2004). The GABA-glutamate connection in schizophrenia: which is the proximate cause? Biochem. Pharmacol. 68, 1507-1514. doi: 10.1016/j.bcp. 2004.07.034

Coyle, J. T., and Tsai, G. (2004). NMDA receptor function, neuroplasticity, and the pathophysiology of schizophrenia. Int. Rev. Neurobiol. 59, 491-515. doi: 10.1016/S0074-7742(04)59019-0

Cui, W. G., Tao, J., Wang, Z. P., Ren, M. X., Zhang, Y. H., Sun, Y., et al. (2013). Neuregulin $1 \beta 1$ antagonizes apoptosis via ErbB4-dependent activation of PI3-kinase/Akt in APP/PS1 transgenic mice. Neurochem. Res. 38, 2237-2246. doi: 10.1007/s11064-013-1131-Z

Dai, Y. N., Zhu, J. Z., Fang, Z. Y., Zhao, D. J., Wan, W. Y., Zhu, H. T., et al. (2015). A case-control study: association between serum neuregulin 4 level and non-alcoholic fatty liver disease. Metabolism 64, 1667-1673. doi: 10.1016/j. metabol.2015.08.013

Dang, R., Guo, Y., Cai, H., Yang, R., Liang, D., Lv, C., et al. (2016). Effects of prolonged antipsychotic administration on neuregulin-1/ErbB signaling in rat prefrontal cortex and myocardium: implications for the therapeutic action and cardiac adverse effect. J. Toxicol. Sci. 41, 303-309. doi: 10.2131/jts.41.303

Depboylu, C., Höllerhage, M., Schnurrbusch, S., Ries, V., Brundin, P., Oertel, W. H., et al. (2013). Neuregulin-1 receptor ErbB4 is upregulated in human midbrain dopaminergic neurons in Parkinson disease and in vitro Parkinson-models. Neurosci. Lett. 531, 209-214. doi: 10.1016/j.neulet.2012. 10.050

Depboylu, C., Rösler, T. W., de Andrade, A., Oertel, W. H., and Hoglinger, G. U. (2015). Systemically administered neuregulin-1 11 rescues nigral dopaminergic neurons via the ErbB4 receptor tyrosine kinase in MPTP mouse models of Parkinson's disease. J. Neurochem. 133, 590-597. doi: 10.1111/jnc. 13026

Díez, A., Cieza-Borrella, C., Suazo, V., González-Sarmiento, R., Papiol, S., and Molina, V. (2014). Cognitive outcome and $\gamma$ noise power unrelated to neuregulin 1 and 3 variation in schizophrenia. Ann. Gen. Psychiatry 13:18. doi: $10.1186 / 1744-859 X-13-18$

Dobson, C. M. (2003). Protein folding and misfolding. Nature 426, 884-890. doi: 10.1038/nature02261

Domschke, K., and Dannlowski, U. (2010). Imaging genetics of anxiety disorders. NeuroImage 53, 822-831. doi: 10.1016/j.neuroimage.2009.11.042

Dorsey, E. R., George, B. P., Bruce, L., and Willis, A. W. (2013a). The coming crisis: obtaining care for the growing burden of neurodegenerative conditions. Neurology 80, 1989-1996. doi: 10.1212/WNL.0b013e318293e2ce

Dorsey, E. R., George, B. P., Leef, B., and Willis, A. W. (2013b). The coming crisis: obtaining care for the growing burden of neurodegenerative conditions. Neurology 80, 1989-1996. doi: 10.1212/WNL.0b013e318293e2ce

Elamin, M., Bede, P., Byrne, S., Jordan, N., Gallagher, L., Wynne, B., et al. (2013). Cognitive changes predict functional decline in ALS: a populationbased longitudinal study. Neurology 80, 1590-1597. doi: 10.1212/WNL. 0b013e31828f18ac

Fallin, M. D., Lasseter, V. K., Avramopoulos, D., Nicodemus, K. K., Wolyniec, P. S., McGrath, J. A., et al. (2005). Bipolar I disorder and schizophrenia: a 440-singlenucleotide polymorphism screen of 64 candidate genes among Ashkenazi Jewish case-parent trios. Am. J. Hum. Genet. 77, 918-936. doi: 10.1086/ 497703

Falls, D. (2003). Neuregulins: functions, forms, and signaling strategies. Exp. Cell Res. 284, 14-30. doi: 10.1016/s0014-4827(02)00102-7

Fiona, M., Pritchard, A. L., Herlina, H., Sayeed, H., Roger, H., Peter, B., et al. (2010). No association between neuregulin 1 and psychotic symptoms in Alzheimer's disease patients. J. Alzheimers Dis. 20, 561-567. doi: 10.3233/JAD2010-1405

Flames, N., Long, J. E., Garratt, A. N., Fischer, T. M., Gassmann, M., Birchmeier, C., et al. (2004). Short- and long-range attraction of cortical GABAergic interneurons by neuregulin-1. Neuron 44, 251-261. doi: 10.1016/j. neuron.2004.09.028 
Fledrich, R., Akkermann, D., Schütza, V., Abdelaal, T. A., Hermes, D., Schäffner, E., et al. (2019). NRG1 type I dependent autoparacrine stimulation of Schwann cells in onion bulbs of peripheral neuropathies. Nat. Commun. 10:1467. doi: 10.1038/s41467-019-09385-6

Fledrich, R., Stassart, R. M., Klink, A., Rasch, L. M., Prukop, T., Haag, L., et al. (2014). Soluble neuregulin-1 modulates disease pathogenesis in rodent models of Charcot-Marie-Tooth disease 1A. Nat. Med. 20, 1055-1061. doi: $10.1038 / \mathrm{nm} .3664$

Fleisig, H., El-Din El-Husseini, A., and Vincent, S. R. (2004). Regulation of ErbB4 phosphorylation and cleavage by a novel histidine acid phosphatase. Neuroscience 127, 91-100. doi: 10.1016/j.neuroscience.2004. 04.060

Fricker, F. R., Ana, A. M., Jorge, G., Remi, P., Federica, L. R., James, P., et al. (2013). Axonal neuregulin 1 is a rate limiting but not essential factor for nerve remyelination. Brain 136, 2279-2297. doi: 10.1093/brain/awt148

Fricker, F. R., Lago, N., Balarajah, S., Tsantoulas, C., Tanna, S., Zhu, N., et al. (2011). Axonally derived neuregulin-1 is required for remyelination and regeneration after nerve injury in adulthood. J. Neurosci. 31, 3225-3233. doi: 10.1523/JNEUROSCI.2568-10.2011

Fusar-Poli, P., Perez, J., Broome, M., Borgwardt, S., Placentino, A., Caverzasi, E., et al. (2007). Neurofunctional correlates of vulnerability to psychosis: a systematic review and meta-analysis. Neurosci. Biobehav. Rev. 31, 465-484. doi: 10.1016/j.neubiorev.2006.11.006

Gallucci, M., Limbucci, N., Catalucci, A., and Caulo, M. (2008). Neurodegenerative diseases. Radiol. Clin. North Am. 46, 799-817. doi: 10.1016/j.rcl.2008.06.002

Gan, J.-L., Cheng, Z.-X., Duan, H.-F., Yang, J.-M., Zhu, X.-Q., and Gao, C.Y. (2014). Atypical antipsychotic drug treatment for 6 months restores $\mathrm{N}$-acetylaspartate in left prefrontal cortex and left thalamus of first-episode patients with early onset schizophrenia: a magnetic resonance spectroscopy study. Psychiatry Res. 223, 23-27. doi: 10.1016/j.pscychresns.2014. 04.010

Gancia, E., De Groot, M., Burton, B., and Clark, D. E. (2017). Discovery of LRRK2 inhibitors by using an ensemble of virtual screening methods. Bioorg. Med. Chem. Lett. 27, 2520-2527. doi: 10.1016/j.bmcl.2017.03.098

Gao, R., Zhang, J., Cheng, L., Wu, X., Dong, W., Yang, X., et al. (2010). A Phase II, randomized, double-blind, multicenter, based on standard therapy, placebocontrolled study of the efficacy and safety of recombinant human neuregulin-1 in patients with chronic heart failure. J. Am. Coll. Cardiol. 55, 1907-1914. doi: 10.1016/j.jacc.2009.12.044

Gassmann, M., and Lemke, G. (1997). Neuregulins and neuregulin receptors in neural development. Curr. Opin. Neurobiol. 7, 87-92. doi: 10.1016/s09594388(97)80125-0

Gaudet, P., Livstone, M. S., Lewis, S. E., and Thomas, P. D. (2011). Phylogeneticbased propagation of functional annotations within the Gene Ontology consortium. Brief Bioinform. 12, 449-462. doi: 10.1093/bib/bbr042

Gerecke, K. M., Wyss, J. M., and Carroll, S. L. (2004). Neuregulin-1 $\beta$ induces neurite extension and arborization in cultured hippocampal neurons. Mol. Cell. Neurosci. 27, 379-393. doi: 10.1016/j.mcn.2004.08.001

Geyer, C. E., Forster, J., Lindquist, D., Chan, S., Romieu, C. G., Pienkowski, T., et al. (2006). Lapatinib plus capecitabine for HER2-positive advanced breast cancer. N. Engl. J. Med. 355, 2733-2743. doi: 10.1056/NEJMoa064320

Goedert, M., and Spillantini, M. G. (2006). A century of Alzheimer's disease. Science 314, 777-781. doi: 10.1126/science.1132814

Grundke-Iqbal, I., Iqbal, K., Tung, Y. C., Quinlan, M., Wisniewski, H. M., and Binder, L. I. (1986). Abnormal phosphorylation of the microtubule-associated protein tau (tau) in Alzheimer cytoskeletal pathology. Proc. Natl. Acad. Sci. U S A 83, 4913-4917. doi: 10.1073/pnas.83.13.4913

Hama, Y., Yabe, I., Wakabayashi, K., Kano, T., Hirotani, M., Iwakura, Y., et al. (2015). Level of plasma neuregulin-1 SMDF is reduced in patients with idiopathic Parkinson's disease. Neurosci. Lett. 587, 17-21. doi: 10.1016/j.neulet. 2014.12.024

Hara, Y., Mckeehan, N., and Fillit, H. M. (2019). Translating the biology of aging into novel therapeutics for Alzheimer disease. Neurology 92, 84-93. doi: 10.1212/WNL.0000000000006745

Harari, D., Tzahar, E., Romano, J., Shelly, M., Pierce, J. H., Andrews, G. C., et al. (1999). Neuregulin-4: a novel growth factor that acts through the ErbB-4 receptor tyrosine kinase. Oncogene 18, 2681-2689. doi: 10.1038/sj.onc.12 02631
Hardiman, O., Al-Chalabi, A., Chio, A., Corr, E. M., Logroscino, G., Robberecht, W., et al. (2017). Amyotrophic lateral sclerosis. Nat. Rev. Dis. Primers 3:17071. doi: 10.1038/nrdp.2017.71

Harrison, P. J. (2004). The hippocampus in schizophrenia: a review of the neuropathological evidence and its pathophysiological implications. Psychopharmacology 174, 151-162. doi: 10.1007/s00213-003-1761-y

Harrison, P. J., and Law, A. J. (2006). Neuregulin 1 and schizophrenia: genetics, gene expression and neurobiology. Biol. Psychiatry 60, 132-140. doi: 10.1016/j. biopsych.2005.11.002

Harrison, P. J., and Weinberger, D. R. (2005). Schizophrenia genes, gene expression, and neuropathology: on the matter of their convergence. Mol. Psychiatry 10, 40-68. doi: 10.1038/sj.mp.4001558

Hayes, N. V., Blackburn, E., Boyle, M. M., Russell, G. A., Frost, T. M., Morgan, B. J., et al. (2010). Expression of neuregulin 4 splice variants in normal human tissues and prostate cancer and their effects on cell motility. Endocr. Relat. Cancer 18, 39-49. doi: 10.1677/ERC-10-0112

He, L., Vanlandewijck, M., Andaloussi Mäe, M., Andrae, J., Ando, K., Del Gaudio, F., et al. (2018). Data descriptor: single cell RNAseq of mouse brain and lung vascular and vessel-associated cell types. Sci. Data 5:180160. doi: 10.1038/sdata.2018.160

Hedhli, N., Kalinowski, A., and Russell, K. S. (2014). Cardiovascular effects of neuregulin-1/ErbB signaling: role in vascular signaling and angiogenesis. Curr. Pharm. Des. 20, 4899-4905. doi: 10.2174/1381612819666131125151058

Hidalgo, A., Kinrade, E. F. V., and Georgiou, M. J. D. C. (2001). The Drosophila neuregulin vein maintains glial survival during axon guidance in the CNS. Dev. Cell 1, 679-690. doi: 10.1016/s1534-5807(01)00074-0

Hijazi, M. M., Thompson, E. W., Tang, C., Coopman, P., Torri, J. A., Yang, D., et al. (2000). Heregulin regulates the actin cytoskeleton and promotes invasiveproperties in breast cancer cell lines. Int. J. Oncol. 17, 629-641. doi: $10.3892 /$ ijo.17.4.629

Ho, W. H., Armanini, M. P., Nuijens, A., Phillips, H. S., and Osheroff, P. L. (1995). Sensory and motor neuron-derived factor. A novel heregulin variant highly expressed in sensory and motor neurons. J. Biol. Chem. 270, 14523-14532. doi: $10.1074 / j b c .270 .24 .14523$

Hobbs, S. S., Cameron, E. M., Hammer, R. P., Le, A. T., Gallo, R. M., Blommel, E. N., et al. (2004). Five carboxyl-terminal residues of neuregulin2 are critical for stimulation of signaling by the ErbB4 receptor tyrosine kinase. Oncogene 23, 883-893. doi: 10.1038/sj.onc. 1207250

Hogan, D. B. (2014). Long-term efficacy and toxicity of cholinesterase inhibitors in the treatment of Alzheimer disease. Can. J. Psychiatry 59, 618-623. doi: $10.1177 / 070674371405901202$

Holbro, T., and Hynes, N. E. (2004). ErbB receptors: directing key signaling networks throughout life. Annu. Rev. Pharmacol. Toxicol. 44, 195-217. doi: 10.1146/annurev.pharmtox.44.101802.121440

Hurvitz, S. A., Hu, Y., O’Brien, N., and Finn, R. S. (2013). Current approaches and future directions in the treatment of HER2-positive breast cancer. Cancer Treat. Rev. 39, 219-229. doi: 10.1016/j.ctrv.2012.04.008

Ieguchi, K., Fujita, M., Ma, Z., Davari, P., Taniguchi, Y., Sekiguchi, K., et al. (2010). Direct binding of the EGF-like domain of neuregulin-1 to integrins (alphavbeta3 and alpha6beta4) is involved in neuregulin-1/ErbB signaling. J. Biol. Chem. 285, 31388-31398. doi: 10.1074/jbc.M110.113878

Inkster, B., Nichols, T. E., Saemann, P. G., Auer, D. P., Holsboer, F., Muglia, P., et al. (2010). Pathway-based approaches to imaging genetics association studies: Wnt signaling, GSK3 $\beta$ substrates and major depression. NeuroImage 53, 908-917. doi: 10.1016/j.neuroimage.2010.02.065

Irene, L., Goldman, J. G., Troster, A. I., Schmand, B. A., Daniel, W., Petersen, R. C., et al. (2012). Diagnostic criteria for mild cognitive impairment in Parkinson's disease: movement disorder society task force guidelines. Mov. Disord. 27, 349-356. doi: $10.1002 / \mathrm{mds} .24893$

Jacobsen, N. E., Abadi, N., Sliwkowski, M. X., Reilly, D., Skelton, N. J., and Fairbrother, W. J. (1996). High-resolution solution structure of the EGF-like domain of heregulin- $\alpha$. Biochemistry 35, 3402-3417. doi: 10.1021/bi9526261

Javitt, D. C. (2004). Glutamate as a therapeutic target in psychiatric disorders. Mol. Psychiatry 9, 984-997, 979. doi: 10.1038/sj.mp.4001551

Jiang, Q., Chen, S., Hu, C., Huang, P., Shen, H., and Zhao, W. (2016). Neuregulin1 (Nrg1) signaling has a preventive role and is altered in the frontal cortex under the pathological conditions of Alzheimer's disease. Mol. Med. Rep. 14, 2614-2624. doi: $10.3892 / \mathrm{mmr} .2016 .5542$ 
Kaplin, A. I., and Montel, W. (2007). How common are the "common" neurologic disorders? Neurology 69, 410-411. doi: 10.1212/01.wnl.0000278071. 91524.4d

Kataria, H., Alizadeh, A., and Karimi-Abdolrezaee, S. (2019). Neuregulin-1/ErbB network: an emerging modulator of nervous system injury and repair. Prog. Neurobiol. 180:101643. doi: 10.1016/j.pneurobio.2019.101643

Kato, T., Kasai, A., Mizuno, M., Liang, F., Shintani, N., Maeda, S., et al. (2009). Phenotypic characterization of transgenic mice overexpressing neuregulin-1. PLoS One 5:e14185. doi: 10.1371/journal.pone.0014185

Khanam, H., Ali, A., Asif, M., and Shamsuzzaman. (2016). Neurodegenerative diseases linked to misfolded proteins and their therapeutic approaches: a review. Eur. J. Med. Chem. 124, 1121-1141. doi: 10.1016/j.ejmech.2016.08.006

Kwon, M. J., Han, M. H., Bagley, J. A., Hyeon, D. Y., Ko, B. S., Lee, Y. M., et al. (2018). Coiled-coil structure-dependent interactions between polyQ proteins and Foxo lead to dendrite pathology and behavioral defects. Proc. Natl. Acad. Sci. U S A 115, E10748-E10757. doi: 10.1073/pnas.1807206115

Lasiene, J., Komine, O., Fujimori-Tonou, N., Powers, B., Endo, F., Watanabe, S., et al. (2016). Neuregulin 1 confers neuroprotection in SOD1-linked amyotrophic lateral sclerosis mice via restoration of C-boutons of spinal motor neurons. Acta Neuropathol. Commun. 4:15. doi: 10.1186/s40478-0160286-7

Lee, H., Akita, R. W., Sliwkowski, M. X., and Maihle, N. J. (2001). A naturally occurring secreted human ErbB3 receptor isoform inhibits heregulinstimulated activation of ErbB2, ErbB3, and ErbB4. Cancer Res. 61, 4467-4473.

Lee, S., and Kim, H.-J. (2015). Prion-like mechanism in amyotrophic lateral sclerosis: are protein aggregates the key? Exp. Neurobiol. 24, 1-7. doi: 10.5607/en.2015.24.1.1

Lee, K.-H., Lee, H., Yang, C. H., Ko, J.-S., Park, C.-H., Woo, R.-S., et al. (2015). Bidirectional signaling of neuregulin-2 mediates formation of GABAergic synapses and maturation of glutamatergic synapses in newborn granule cells of postnatal hippocampus. J. Neurosci. 35, 16479-16493. doi: 10.1523/JNEUROSCI.1585-15.2015

Lemke, G. E., and Brockes, J. P. (1984). Identification and purification of glial growth factor. J. Neurosci. 4, 75-83. doi: 10.1523/JNEUROSCI.04-01-00 075.1984

Li, D., Collier, D. A., and He, L. (2006). Meta-analysis shows strong positive association of the neuregulin 1 (NRG1) gene with schizophrenia. Hum. Mol. Genet. 15, 1995-2002. doi: 10.1093/hmg/ddl122

Li, J., Jin, M., Wang, L., Qin, B., and Wang, K. (2017). MDS clinical diagnostic criteria for Parkinson's disease in China. J. Neurol. 264, 476-481. doi: 10.1007/s00415-016-8370-2

Li, B., Woo, R.-S., Mei, L., and Malinow, R. (2007). The neuregulin-1 receptor erbB4 controls glutamatergic synapse maturation and plasticity. Neuron 54, 583-597. doi: 10.1016/j.neuron.2007.03.028

Li, Y., Xu, Z., Ford, G. D., Croslan, D. R., Cairobe, T., Li, Z., et al. (2007). Neuroprotection by neuregulin-1 in a rat model of permanent focal cerebral ischemia. Brain Res. 1184, 277-283. doi: 10.1016/j.brainres.2007.09.037

Lim, J., and Yue, Z. (2015). Neuronal aggregates: formation, clearance, and spreading. Dev Cell 32, 491-501. doi: 10.1016/j.devcel.2015.02.002

Lipska, B. K. (2004). Using animal models to test a neurodevelopmental hypothesis of schizophrenia. J. Psychiatry Neurosci. 29, 282-286.

Liu, J., Allender, E., Wang, J., Simpson, E. H., Loeb, J. A., and Song, F. (2018). Slowing disease progression in the SOD1 mouse model of ALS by blocking neuregulin-induced microglial activation. Neurobiol. Dis. 111, 118-126. doi: 10.1016/j.nbd.2017.12.012

Liu, X. H., Bates, R., Yin, D.-M., Shen, C. Y., Wang, F., Su, N., et al. (2011). Specific regulation of NRG1 isoform expression by neuronal activity. J. Neurosci. 31, 8491'8501. doi: 10.1523/JNEUROSCI.5317-10.2011

Longart, M., Liu, Y., Karavanova, I., and Buonanno, A. (2004). Neuregulin2 is developmentally regulated and targeted to dendrites of central neurons. J. Comp. Neurol. 472, 156-172. doi: 10.1002/cne.20016

Loos, M., Mueller, T., Gouwenberg, Y., Wijnands, R., van der Loo, R. J., Neuro, B. M., et al. (2014). Neuregulin-3 in the mouse medial prefrontal cortex regulates impulsive action. Biol. Psychiatry 76, 648-655. doi: 10.1016/j. biopsych.2014.02.011

Luck, K., Kim, D.-K., Lambourne, L., Spirohn, K., Begg, B. E., Bian, W., et al. (2020). A reference map of the human binary protein interactome. Nature 580, 402-408. doi: 10.1038/s41586-020-2188-x
Lydia, P., Proietti, C. J., Proiettii, C. J., Leticia, L., Mariana, S., BalañÁ, M. E., et al. (2002). Heregulin inhibits proliferation via ERKs and phosphatidylinositol 3-kinase activation but regulates urokinase plasminogen activator independently of these pathways in metastatic mammary tumor cells. Int. J. Cancer 100, 642-653. doi: 10.1002/ijc.10533

Malek, N., Lawton, M. A., Grosset, K. A., Bajaj, N., Barker, R. A., Ben-Shlomo, Y., et al. (2017). Utility of the new movement disorder society clinical diagnostic criteria for Parkinson's disease applied retrospectively in a large cohort study of recent onset cases. Parkinsonism Relat. Disord. 40, 40-46. doi: 10.1016/j. parkreldis.2017.04.006

Mancuso, R., Martínez-Muriana, A., Leiva, T., Gregorio, D., Ariza, L., Morell, M., et al. (2016). Neuregulin-1 promotes functional improvement by enhancing collateral sprouting in SOD1(G93A) ALS mice and after partial muscle denervation. Neurobiol. Dis. 95, 168-178. doi: 10.1016/j.nbd.2016. 07.023

Mandelker, D., Gabelli, S. B., Schmidt-Kittler, O., Zhu, J., Cheong, I., Huang, C. H. et al. (2009). A frequent kinase domain mutation that changes the interaction between PI3K $\alpha$ and the membrane. Proc. Natl. Acad. Sci. U S A 106, 16996-17001. doi: 10.1073/pnas.0908444106

Mariana, D., Prakash, S., Rebecca, C., Edith, B., Neil, L., Raj, R., et al. (2010). Coexpression of neuregulins 1, 2, 3 and 4 in human breast cancer. J. Pathol. 203, 672-680. doi: 10.1002/path.1561

Marone, R., Hess, D., Dankort, D., Muller, W. J., Hynes, N. E., and Badache, A. (2004). Memo mediates ErbB2-driven cell motility. Nat. Cell Biol. 6, 515-522. doi: $10.1038 /$ ncb1134

Massagué, J., and Pandiella, A. (1993). Membrane-anchored growth factors. Annu. Rev. Biochem. 62, 515-541. doi: 10.1146/annurev.bi.62.070193. 002503

Masters, C. L., Bateman, R., Blennow, K., Rowe, C. C., Sperling, R. A., and Cummings, J. L. (2015). Alzheimer's disease. Nat. Rev. Dis. Primers 1:15056. doi: $10.1038 /$ nrdp.2015.56

McBain, C. J., and Fisahn, A. (2001). Interneurons unbound. Nat. Rev. Neurosci. 2, 11-23. doi: 10.1038/35049047

McElroy, S. J., Castle, S. L., Bernard, J. K., Almohazey, D., Hunter, C. J., Bell, B. A., et al. (2014). The ErbB4 ligand neuregulin-4 protects against experimental necrotizing enterocolitis. Am. J. Pathol. 184, 2768-2778. doi: 10.1016/j.ajpath. 2014.06.015

Mehta, P., Kaye, W., Bryan, L., Larson, T., Copeland, T., and Wu, J. (2016). Prevalence of amyotrophic lateral sclerosis-united states, 2012-2013. MMWR Surveill. Summ. 65, 1-12. doi: 10.15585/mmwr.ss6508a1

Mei, L., and Xiong, W.-C. (2008). Neuregulin 1 in neural development, synaptic plasticity and schizophrenia. Nat. Rev. Neurosci. 9, 437-452. doi: $10.1038 / \mathrm{nrn} 2392$

Meier, S., Strohmaier, J., Breuer, R., Mattheisen, M., Degenhardt, F., Muhleisen, T. W., et al. (2013). Neuregulin 3 is associated with attention deficits in schizophrenia and bipolar disorder. Int. J. Neuropsychopharmacol. 16, 549-556. doi: 10.1017/S1461145712000697

Meyer, D., and Birchmeier, C. (1995). Multiple essential functions of neuregulin in development. Nature 378, 386-390. doi: 10.1038/378386a0

Meyer, D., Yamaai, T., Garratt, A., Riethmacher-Sonnenberg, E., Kane, D., Theill, L. E., et al. (1997). Isoform-specific expression and function of neuregulin. Development 124, 3575-3586.

Michailov, G. V., Sereda, M. W., Brinkmann, B. G., Fischer, T. M., Haug, B., Birchmeier, C., et al. (2004). Axonal neuregulin-1 regulates myelin sheath thickness. Science 304, 700-703. doi: 10.1126/science.1095862

Miller, M. W., Mooney, S. M., and Middleton, F. A. (2006). Transforming growth factor $\beta 1$ and ethanol affect transcription and translation of genes and proteins for cell adhesion molecules in B104 neuroblastoma cells. J. Neurochem. 97, 1182-1190. doi: 10.1111/j.1471-4159.2006.03858.x

Mòdol-Caballero, G., Herrando-Grabulosa, M., García-Lareu, B., Solanes, N., Verdés, S., Osta, R., et al. (2020). Gene therapy for overexpressing Neuregulin 1 type $\mathrm{I}$ in skeletal muscles promotes functional improvement in the SOD1(G93A) ALS mice. Neurobiol. Dis. 137:104793. doi: 10.1016/j.nbd.2020. 104793

Morimoto, B. (2010). Drug development for neurodegenerative diseases-second annual marcus evans conference. Advances in drug development for NDD and expediting discovery through novel compounds and sound clinical trials. IDrugs 13, 440-443. 
Mostaid, M. S., Lloyd, D., Liberg, B., Sundram, S., Pereira, A., and Pantelis, C. (2016). Neuregulin-1 and schizophrenia in the genome-wide association study era. Neurosci. Biobehav. Rev. 68, 387-409. doi: 10.1016/j.neubiorev.2016.06.001

Müller, T., Braud, S., Jüttner, R., Voigt, B. C., Paulick, K., Sheean, M. E., et al. (2018). Neuregulin 3 promotes excitatory synapse formation on hippocampal interneurons. Embo J. 37:e98858. doi: 10.15252/embj.201798858

Munro, K. M., Nash, A., Pigoni, M., Lichtenthaler, S. F., and Gunnersen, J. M. (2016). Functions of the Alzheimer's disease protease BACE1 at the synapse in the central nervous system. J. Mol. Neurosci. 60, 305-315. doi: 10.1007/s12031016-0800-1

Nakano, N., Higashiyama, S., Ohmoto, H., Ishiguro, H., Taniguchi, N., and Wada, Y. (2004). The N-terminal region of NTAK/neuregulin-2 isoforms has an inhibitory activity on angiogenesis. J. Biol. Chem. 279, 11465-11470. doi: 10.1074/jbc.M311045200

Nakano, N., Kanekiyo, K., Nakagawa, T., Asahi, M., and Ide, C. (2016). NTAK/neuregulin-2 secreted by astrocytes promotes survival and neurite outgrowth of neurons via ErbB3. Neurosci. Lett. 622, 88-94. doi: 10.1016/j. neulet.2016.04.050

Neumann, M., Sampathu, D. M., Kwong, L. K., Truax, A. C., Micsenyi, M. C., Chou, T. T., et al. (2006). Ubiquitinated TDP-43 in frontotemporal lobar degeneration and amyotrophic lateral sclerosis. Science 314, 130-133. doi: $10.1126 /$ science. 1134108

Nielsen, T. O., Friis-Hansen, L., Poulsen, S. S., Federspiel, B., and Sorensen, B. S. (2014). Expression of the EGF family in gastric cancer: downregulation of HER4 and its activating ligand NRG4. PLoS One 9:e94606. doi: 10.1371/journal. pone.0094606

Norton, N., Williams, H. J., and Owen, M. J. (2006). An update on the genetics of schizophrenia. Curr. Opin. Psychiatry 19, 158-164. doi: 10.1097/01.yco. 0000214341.52249 .59

Ntsapi, C., and Loos, B. (2016). Caloric restriction and the precisioncontrol of autophagy: a strategy for delaying neurodegenerative disease progression. Exp. Gerontol. 83, 97-111. doi: 10.1016/j.exger.2016. 07.014

Nucifora, L. G., MacDonald, M. L., Lee, B. J., Peters, M. E., Norris, A. L., Orsburn, B. C., et al. (2019). Increased protein insolubility in brains from a subset of patients with schizophrenia. Am. J. Psychiatry 176, 730-743. doi: 10.1176/appi.ajp.2019.18070864

Osheroff, P. L., Tsai, S. P., Chiang, N. Y., King, K. L., Li, R., Lewis, G. D., et al. (1999). Receptor binding and biological activity of mammalian expressed sensory and motor neuron-derived factor (SMDF). Growth Factors 16, 241-253. doi: 10.3109/08977199909002133

Okouchi, M., Ekshyyan, O., Maracine, M., and Aw, T. Y. (2007). Neuronal apoptosis in neurodegeneration. Antioxid. Redox Signal. 9, 1059-1096. doi: 10.1089/ars.2007.1511

Owen, M. J., Sawa, A., and Mortensen, P. B. (2016). Schizophrenia. Lancet 388, 86-97. doi: 10.1016/S0140-6736(15)01121-6

Pan, P., and Dobrowsky, R. T. (2013). Differential expression of neuregulin-1 isoforms and downregulation of erbin are associated with ErbB2 receptor activation in diabetic peripheral neuropathy. Acta Neuropathol. Commun. 1:39. doi: 10.1186/2051-5960-1-39

Pankonin, M. S., Sohi, J., Kamholz, J., and Loeb, J. A. (2009). Differential distribution of neuregulin in human brain and spinal fluid. Brain Res. 1258, 1-11. doi: 10.1016/j.brainres.2008.12.047

Pantelis, C., Yücel, M., Wood, S. J., Velakoulis, D., Sun, D., Berger, G., et al. (2005). Structural brain imaging evidence for multiple pathological processes at different stages of brain development in schizophrenia. Schizophr. Bull. 31, 672-696. doi: 10.1093/schbul/sbi034

Paramo, B., Wyatt, S., and Davies, A. M. (2018). An essential role for neuregulin-4 in the growth and elaboration of developing neocortical pyramidal dendrites. Exp. Neurol. 302, 85-92. doi: 10.1016/j.expneurol.2018.01.002

Paramo, B., Wyatt, S., and Davies, A. M. (2019). Neuregulin-4 is required for the growth and elaboration of striatal medium spiny neuron dendrites. J. Neuropathol. Exp. Neurol. 78, 725-734. doi: 10.1093/jnen/nlz046

Patel, C. N., Georrge, J. J., Modi, K. M., Narechania, M. B., Patel, D. P., Gonzalez, F. J., et al. (2018). Pharmacophore-based virtual screening of catechol-o-methyltransferase (COMT) inhibitors to combat Alzheimer's disease. J. Biomol. Struct. Dyn. 36, 3938-3957. doi: 10.1080/07391102.2017. 1404931
Paterson, C., and Law, A. J. (2014). Transient overexposure of neuregulin 3 during early postnatal development impacts selective behaviors in adulthood. PLoS One 9:e104172. doi: 10.1371/journal.pone.0104172

Patrizia, F., Wong, P.-Y. A., Husted, K. H., Shanshan, L., Liu, V. M., Kohlstaedt, L. A., et al. (2012). Cerebrospinal fluid-based kinetic biomarkers of axonal transport in monitoring neurodegeneration. J. Clin. Invest. 122, 3159-3169. doi: 10.1172/JCI64575

Peles, E., Ben-Levy, R., Tzahar, E., Liu, N., Wen, D., and Yarden, Y. (1993). Cell-type specific interaction of Neu differentiation factor (NDF/heregulin) with Neu/HER-2 suggests complex ligand-receptor relationships. EMBO J. 12, 961-971. doi: 10.1002/j.1460-2075.1993.tb05737.x

Pfeifer, A. (2015). NRG4: an endocrine link between brown adipose tissue and liver. Cell Metab. 21, 13-14. doi: 10.1016/j.cmet.2014.12.008

Phukan, J., Elamin, M., Bede, P., Jordan, N., Gallagher, L., Byrne, S., et al. (2012). The syndrome of cognitive impairment in amyotrophic lateral sclerosis: a population-based study. J. Neurol. Neurosurg. Psychiatry 83, 102-108. doi: 10.1136/jnnp-2011-300188

Pietraszek, M. (2003). Significance of dysfunctional glutamatergic transmission for the development of psychotic symptoms. Pol. J. Pharmacol. 55, 133-154.

Pinkas-Kramarski, R., Eilam, R., Spiegler, O., Lavi, S., Liu, N., Chang, D., et al. (1994). Brain neurons and glial cells express Neu differentiation factor/heregulin: a survival factor for astrocytes. Proc. Natl. Acad. Sci. U S A 91, 9387-9391. doi: 10.1073/pnas.91.20.9387

Przedborski, S. (2017). The two-century journey of Parkinson disease research. Nat. Rev. Neurosci. 18, 251-259. doi: 10.1038/nrn.2017.25

Qiu, M.-Z., He, C.-Y., Lu, S.-X., Guan, W.-L., Wang, F., Wang, X.-J., et al. (2020). Prospective observation: clinical utility of plasma Epstein-Barr virus DNA load in EBV-associated gastric carcinoma patients. Int. J. Cancer 146, 272-280. doi: $10.1002 /$ ijc. 32490

Rahimi-Aliabadi, S., Shahmohammadibeni, N., Jamshidi, J., Shandiz, E. E., Mirfakhraie, R., Ohadi, M., et al. (2017). Association of $\beta$-secretase functional polymorphism with risk of schizophrenia. Genet. Test. Mol. Biomarkers 21, 248-251. doi: 10.1089/gtmb.2016.0262

Raper, J., Stephens, S. B., Sanchez, M., Bachevalier, J., and Wallen, K. (2014). Neonatal amygdala lesions alter mother-infant interactions in rhesus monkeys living in a species-typical social environment. Dev. Psychobiol. 56, 1711-1722. doi: $10.1002 /$ dev.21234

Rehn, A. E., and Rees, S. M. (2005). Investigating the neurodevelopmental hypothesis of schizophrenia. Clin. Exp. Pharmacol. Physiol. 32, 687-696. doi: 10.1111/j.1440-1681.2005.04257.x

Reitz, C., Brayne, C., Mayeux, R. (2011). Epidemiology of Alzheimer disease. Nat. Rev. Neurol. 7, 137-152. doi: 10.1038/nrneurol.2011.2

Riethmacher, D., Sonnenberg-Riethmacher, E., Brinkmann, V., Yamaai, T., Lewin, G. R., and Birchmeier, C. (1997). Severe neuropathies in mice with targeted mutations in the ErbB3 receptor. Nature 389, 725-730. doi: $10.1038 / 39593$

Rosnack, K. J., Stroh, J. G., Singleton, D. H., Guarino, B. C., and Andrews, G. C. (1994). Use of capillary electrophoresis-electrospray ionization mass spectrometry in the analysis of synthetic peptides. J. Chromatogr. A 675, 219-225. doi: 10.1016/0021-9673(94)85275-8

Ross, C. A., and Poirier, M. A. (2005). Opinion: what is the role of protein aggregation in neurodegeneration? Nat. Rev. Mol. Cell Biol. 6, 891-898. doi: $10.1038 / \mathrm{nrm} 1742$

Ryu, J., Hong, B.-H., Kim, Y.-J., Yang, E. J., Choi, M., Kim, H., et al. (2016). Neuregulin-1 attenuates cognitive function impairments in a transgenic mouse model of Alzheimer's disease. Cell Death Dis. 7:e2117. doi: 10.1038/cddis. 2016.30

Ryu, J., Yu, H.-N., Cho, H., Kim, H.-S., Baik, T.-K., Lee, S.-J., et al. (2012). Neuregulin-1 exerts protective effects against neurotoxicities induced by C-terminal fragments of APP via ErbB4 receptor. J. Pharmacol. Sci. 119, 73-81. doi: 10.1254/jphs.12057fp

Sato, Y., Yashiro, M., and Takakura, N. (2013). Heregulin induces resistance to lapatinib-mediated growth inhibition of HER2-amplified cancer cells. Cancer Sci. 104, 1618-1625. doi: 10.1111/cas.12290

Scharinger, C., Rabl, U., Sitte, H. H., and Pezawas, L. (2010). Imaging genetics of mood disorders. NeuroImage 53, 810-821. doi: 10.1016/j.neuroimage.2010. 02.019 
Schneider, M. R., and Eckhard, W. J. (2010). The epidermal growth factor receptor ligands at a glance. J. Cell. Physiol. 218, 460-466. doi: 10.1002/jcp.21635

Schumacher, M. A., Hedl, M., Abraham, C., Bernard, J. K., Lozano, P. R., Hsieh, J. J., et al. (2017). ErbB4 signaling stimulates pro-inflammatory macrophage apoptosis and limits colonic inflammation. Cell Death Dis. 8:e2622. doi: $10.1038 /$ cddis. 2017.42

Selkoe, D. J. (1998). The cell biology of $\beta$-amyloid precursor protein and presenilin in Alzheimer's disease. Trends Cell Biol. 8, 447-453. doi: 10.1016/s09628924(98)01363-4

Shinde, P., Vidyasagar, N., Dhulap, S., Dhulap, A., and Hirwani, R. (2015). Natural products based $\mathrm{P}$-glycoprotein activators for improved $\beta$-amyloid clearance in Alzheimer's disease: an in silico approach. Cent. Nerv. Syst. Agents Med. Chem. 16, 50-59. doi: 10.2174/1871524915666150826092152

Song, F., Chiang, P., Wang, J., Ravits, J., and Loeb, J. A. (2012). Aberrant neuregulin 1 signaling in amyotrophic lateral sclerosis. J. Neuropathol. Exp. Neurol. 71, 104-115. doi: 10.1097/NEN.0b013e3182423c43

Spinedi, E., and Cardinali, D. P. (2019). Neuroendocrine-metabolic dysfunction and sleep disturbances in neurodegenerative disorders: focus on Alzheimer's disease and melatonin. Neuroendocrinology 108, 354-364. doi: $10.1159 / 000494889$

Stavroula, A., Grove, E. A., and Ragsdale, C. W. (2003). Identification of a Pax6-dependent epidermal growth factor family signaling source at the lateral edge of the embryonic cerebral cortex. J. Neurosci. 23, 6399-6403. doi: 10.1523/JNEUROSCI.23-16-06399.2003

Stefansson, H., Sigurdsson, E., Steinthorsdottir, V., Bjornsdottir, S., Sigmundsson, T., Ghosh, S., et al. (2002). Neuregulin 1 and susceptibility to schizophrenia. Am. J. Hum. Genet. 71, 877-892. doi: 10.1086/342734

Steinthorsdottir, V., Stefansson, H., Ghosh, S., Birgisdottir, B., Bjornsdottir, S., Fasquel, A. C., et al. (2004). Multiple novel transcription initiation sites for NRG1. Gene 342, 97-105. doi: 10.1016/j.gene.2004.07.029

Sun, L., Cheng, B., Zhou, Y., Fan, Y., Li, W., Qiu, Q., et al. (2020). ErbB4 mutation that decreased NRG1-ErbB4 signaling involved in the pathogenesis of amyotrophic lateral sclerosis/frontotemporal dementia. J. Alzheimers Dis. 74, 535-544. doi: 10.3233/JAD-191230

Talboom, J. S., Håberg, A., De Both, M. D., Naymik, M. A., Schrauwen, I., Lewis, C. R., et al. (2019). Family history of Alzheimer's disease alters cognition and is modified by medical and genetic factors. Elife 8:e46179. doi: 10.7554/eLife.46179

Taveggia, C., Zanazzi, G., Petrylak, A., Yano, H., Rosenbluth, J., Einheber, S., et al. (2005). Neuregulin-1 type III determines the ensheathment fate of axons. Neuron 47, 681-694. doi: 10.1016/j.neuron.2005.08.017

Trinidad, J. C., and Cohen, J. B. (2004). Neuregulin inhibits acetylcholine receptor aggregation in myotubes. J. Biol. Chem. 279, 31622-31628. doi: 10.1074/jbc. M400044200

van der Graaff, M. M., de Jong, J. M. B., Baas, F., and De Visser, M. (2009). Upper motor neuron and extra-motor neuron involvement in amyotrophic lateral sclerosis: a clinical and brain imaging review. Neuromuscul. Disord. 19, 53-58. doi: 10.1016/j.nmd.2008.10.002

Vullhorst, D., Mitchell, R. M., Keating, C., Roychowdhury, S., Karavanova, I., Tao-Cheng, J. H., et al. (2015). A negative feedback loop controls NMDA receptor function in cortical interneurons via neuregulin 2/ErbB4 signalling. Nat. Commun. 6:7222. doi: 10.1038/ncomms8222

Walss-Bass, C., Liu, W., Lew, D. F., Villegas, R., Montero, P., Dassori, A., et al. (2006). A novel missense mutation in the transmembrane domain of neuregulin 1 is associated with schizophrenia. Biol. Psychiatry 60, 548-553. doi: 10.1016/j.biopsych.2006.03.017

Wang, X., Huang, T., Bu, G., and Xu, H. (2014). Dysregulation of protein trafficking in neurodegeneration. Mol. Neurodegener. 9:31. doi: 10.1186/17501326-9-31

Wang, F., Jiang, T., Sun, Z., Teng, S.-L., Luo, X., Zhu, Z., et al. (2009). Neuregulin 1 genetic variation and anterior cingulum integrity in patients with schizophrenia and healthy controls. J. Psychiatry Neurosci. 34, 181-186.

Wang, R., Wang, Y., Hu, R., Chen, X., Song, M., and Wang, X. (2015). Decreased plasma levels of neureglin-1 in drug naive patients and chronic patients with schizophrenia. Neurosci. Lett. 606, 220-224. doi: 10.1016/j.neulet.2015.09.010

Wang, K.-S., Xu, N., Wang, L., Aragon, L., Ciubuc, R., Arana, T. B., et al. (2014). NRG3 gene is associated with the risk and age at onset of Alzheimer disease. J. Neural Transm. 121, 183-192. doi: 10.1007/s00702-013-1091-0
Wang, G.-X., Zhao, X.-Y., Meng, Z.-X., Kern, M., Dietrich, A., Chen, Z., et al. (2014). The brown fat-enriched secreted factor Nrg4 preserves metabolic homeostasis through attenuation of hepatic lipogenesis. Nat. Med. 20, 1436-1443. doi: 10.1038/nm.3713

Willem, M. (2016). Proteolytic processing of Neuregulin-1. Brain Res. Bull. 126, 178-182. doi: 10.1016/j.brainresbull.2016.07.003

Woo, R.-S., Lee, J.-H., Yu, H.-N., Song, D.-Y., and Baik, T.-K. (2011). Expression of ErbB4 in the neurons of Alzheimer's disease brain and APP/PS1 mice, a model of Alzheimer's disease. Anat. Cell Biol. 44, 116-127. doi: 10.5115/acb.2011.44. 2.116

Woo, R.-S., Li, X.-M., Tao, Y., Carpenter-Hyland, E., Huang, Y. Z., Weber, J., et al. (2007). Neuregulin-1 enhances depolarization-induced GABA release. Neuron 54, 599-610. doi: 10.1016/j.neuron.2007.04.009

Xu, J., De Winter, F., Farrokhi, C., Rockenstein, E., Mante, M., Adame, A., et al. (2016). Neuregulin 1 improves cognitive deficits and neuropathology in an Alzheimer's disease model. Sci. Rep. 6:31692. doi: 10.1038/srep 31692

Xu, J., Hu, C., Chen, S., Shen, H., Jiang, Q., Huang, P., et al. (2017). Neuregulin1 protects mouse cerebellum against oxidative stress and neuroinflammation. Brain Res. 1670, 32-43. doi: 10.1016/j.brainres.2017.06.012

Xu, M., Zhang, D.-F., Luo, R., Wu, Y., Zhou, H., Kong, L.-L., et al. (2018). A systematic integrated analysis of brain expression profiles reveals YAP1 and other prioritized hub genes as important upstream regulators in Alzheimer's disease. Alzheimers Dement. 14, 215-229. doi: 10.1016/j.jalz.2017. 08.012

Yamada, K., Ichino, N., Nishii, K., Sawada, H., Higashiyama, S., Ishiguro, H., et al. (2000). Characterization of the human NTAK gene structure and distribution of the isoforms for rat NTAK mRNA. Gene 255, 15-24. doi: 10.1016/s03781119(00)00309-7

Yan, L., Shamir, A., Skirzewski, M., Leiva-Salcedo, E., Kwon, O. B., Karavanova, I., et al. (2018). Neuregulin-2 ablation results in dopamine dysregulation and severe behavioral phenotypes relevant to psychiatric disorders. Mol. Psychiatry 23, 1233-1243. doi: 10.1038/mp.2017.22

Yang, X., Kuo, Y., Devay, P., Yu, C., and Role, L. (1998). A cysteine-rich isoform of neuregulin controls the level of expression of neuronal nicotinic receptor channels during synaptogenesis. Neuron 20, 255-270. doi: 10.1016/s08966273(00)80454-7

Yarden, Y. (2001). The EGFR family and its ligands in human cancer. signalling mechanisms and therapeutic opportunities. Eur. J. Cancer 37, S3-S8. doi: 10.1016/s0959-8049(01)00230-1

Yonesaka, K., Zejnullahu, K., Okamoto, I., Satoh, T., Cappuzzo, F., Souglakos, J., et al. (2011). Activation of ERBB2 signaling causes resistance to the EGFR-directed therapeutic antibody cetuximab. Sci. Transl. Med. 3:99ra86. doi: $10.1126 /$ scitranslmed. 3002442

Zhang, Y., Chen, K., Sloan, S. A., Bennett, M. L., Scholze, A. R., O’Keeffe, S., et al. (2014). An RNA-sequencing transcriptome and splicing database of glia, neurons, and vascular cells of the cerebral cortex. J. Neurosci. 34, 11929-11947. doi: 10.1523/JNEUROSCI.1860-14.2014

Zhang, D.-F., Fan, Y., Xu, M., Wang, G., Wang, D., Li, J., et al. (2019). Complement C7 is a novel risk gene for Alzheimer's disease in Han Chinese. Natl. Sci. Rev. 6, 257-274. doi: 10.1093/nsr/nwy127

Zhang, Y., and Hamburger, A. W. (2004). Heregulin regulates the ability of the ErbB3-binding protein Ebp1 to bind E2F promoter elements and repress E2F-mediated transcription. J. Biol. Chem. 279, 26126-26133. doi: 10.1074/jbc. M314305200

Zhang, D. X., Sliwkowski, M. X., Mark, M., Frantz, G., Akita, R., Sun, Y., et al. (1997). Neuregulin-3 (NRG3): a novel neural tissue-enriched protein that binds and activates ErbB4. Proc. Natl. Acad. Sci. U S A 94, 9562-9567. doi: 10.1073/pnas.94.18.9562

Zhao, W.-J. (2013a). "Neuregulin-1 (Nrg1): an emerging regulator of prolactin (PRL) secretion," in IntechOpen, Chapter 5. doi: 10.5772/ 54716

Zhao, W.-J. (2013b). The expression and localization of neuregulin-1 (Nrg1) in the gastrointestinal system of the rhesus monkey. Folia Histochem. Cytobiol. 51, 38-44. doi: 10.5603/FHC.2013.006

Zhao, W.-J., Jiang, Q., and Mei, J.-P. (2015). Neurohypophyseal neuregulin 1 is derived from the hypothalamus as a potential prolactin modulator. Neuroendocrinology 102, 288-299. doi: 10.1159/000431377 
Zhao, Y. Y., Sawyer, D. R., Baliga, R. R., Opel, D. J., Han, X., Marchionni, M. A., et al. (1998). Neuregulins promote survival and growth of cardiac myocytes. Persistence of ErbB2 and ErbB4 expression in neonatal and adult ventricular myocytes. J. Biol. Chem. 273, 10261-10269. doi: 10.1074/jbc.273.17. 10261

Zhao, W. J., and Ren, S. G. (2011a). Endogenous neuregulin-1 expression in the anterior pituitary of female Wistar-Furth rats during the estrous cycle. Nan Fang Yi Ke Da Xue Xue Bao 31, 921-927.

Zhao, W. J., and Ren, S.-G. (2011b). Neuregulin-1 (Nrg1) is mainly expressed in rat pituitary gonadotroph cells and possibly regulates prolactin (PRL) secretion in a juxtacrine manner. J. Neuroendocrinol. 23, 1252-1262. doi: 10.1111/j.13652826.2011.02223.x

Zhao, W. J., Shen, Y. Q., and Ren, S. G. (2011). Endogenous expression of Neuregulin-1 (Nrg1) as a potential modulator of prolactin (PRL) secretion in GH3 cells. Cell Tissue Res. 344, 313-320. doi: 10.1007/s00441-011-1157-y

Zhou, L., Fisher, M. L., Cole, R. D., Gould, T. J., Parikh, V., Ortinski, P. I., et al. (2018). Neuregulin 3 signaling mediates nicotine-dependent synaptic plasticity in the orbitofrontal cortex and cognition. Neuropsychopharmacology 43, 1343-1354. doi: 10.1038/npp.2017.278

Zhou, Y., Li, Y., Meng, Y., Wang, J., Wu, F., Ning, Y., et al. (2020). Neuregulin 3 rs10748842 polymorphism contributes to the effect of body mass index on cognitive impairment in patients with schizophrenia. Transl. Psychiatry 10:62. doi: $10.1038 /$ s41398-020-0746-5

Conflict of Interest: The authors declare that the research was conducted in the absence of any commercial or financial relationships that could be construed as a potential conflict of interest.

Copyright (c) $2021 \mathrm{Ou}$, Lin, and Zhao. This is an open-access article distributed under the terms of the Creative Commons Attribution License (CC BY). The use, distribution or reproduction in other forums is permitted, provided the original author(s) and the copyright owner(s) are credited and that the original publication in this journal is cited, in accordance with accepted academic practice. No use, distribution or reproduction is permitted which does not comply with these terms. 